\begin{tabular}{|l|l|l|l|l|}
\hline $\begin{array}{l}\text { Cuadernos de Investigación Geográfica } \\
\text { Geographical Research Letters }\end{array}$ & 2020 & N $^{\circ} 46(1)$ & pp. 251-283 & eISSN 1697-9540 \\
\hline
\end{tabular}

\title{
MODELADO NUMÉRICO DE LAS OSCILACIONES FRONTALES Y OCURRENCIA DE FORMACIÓN DE DIQUES DE HIELO DEL GLACIAR PERITO MORENO, CAMPO DE HIELO PATAGÓNICO SUR
}

\author{
E. LANNUTTI ${ }^{1 *}$, M.G. LENZANO ${ }^{1}$, M. DURAND ${ }^{1}$, \\ A. LO VECCHIO ${ }^{1}$, S. MORAGUES ${ }^{1}$, L. LENZANO ${ }^{1,2}$ \\ ${ }^{1}$ Instituto Argentino de Nivología, Glaciología y Ciencias Ambientales (IANIGLA)- \\ Centro Científico Tecnológico (CCT), CONICET, 5500 Mendoza, Argentina.
}

${ }^{2}$ Facultad de Filosofía y Letras, Universidad Nacional de Cuyo, M5502JMA Mendoza, Argentina.

RESUMEN. En el presente estudio, se aborda el diseño y desarrollo de un modelo numérico computacional del comportamiento del ciclo oscilatorio estacional de avance y retroceso del glaciar Perito Moreno, denominado MO-ACAR. Dentro de su comportamiento oscilatorio, en algunos años el glaciar avanza y alcanza la Península de Magallanes formando un dique de hielo. Por ello, el objetivo del MO-ACAR es simular la posición frontal diaria del glaciar y la ocurrencia de eventos de formación de los diques de hielo durante el periodo 1994-2018. El modelo fue calibrado y validado a partir de un proceso de optimización iterativo, basado en la maximización de valores de correlación y minimización de errores de distancia. La simulación de la ocurrencia de la formación de diques de hielo y la oscilación de la posición frontal lograron altas prestaciones, alcanzando óptimos valores de correlación $(0,99)$ y bajos errores de posición $(9,56 \pm 13,94$ $m)$, respectivamente. Los resultados demuestran que la dinámica del glaciar y la formación de los diques de hielo responden a distintas escalas temporales. En periodos cortos-intermedios de tiempo (escalas diarias-estacionales), la ocurrencia depende tanto de las características propias del evento, como de la fase e intensidad del evento previo. En periodos prolongados (escalas mayores a un año), la modulación de baja frecuencia de la velocidad del flujo de hielo, provocada por las variaciones de temperatura del aire, controla los periodos con formación de diques de hielo y libres de éstos.

Numerical modelling of ice-front oscillations and ice-dam occurrence at Glaciar Perito Moreno, the Southern Patagonia Icefield

ABSTRACT. The present study conducts the design and development of a computational numerical model to describe the behavior of the seasonal 
oscillatory cycle of advance and recession of the Perito Moreno glacier, named MO-ACAR. Within its oscillatory behavior, in some years the glacier advances and reaches the Magellan Peninsula forming an ice-dam that break down due to the water pressure of the lake after a certain time. Thus, the main goal of the MO-ACAR model is to simulate the daily ice-front position of the glacier and the events occurrence of the ice-dam formation during 1994-2018 period. The model is calibrated and validated from an iterative optimization process, based on the maximization of correlation values and minimization of distance errors to the Magallanes Peninsula. The simulation of the ice-dam's formation and the oscillation of the frontal position achieved high performance, reaching optimal correlation values (0.99) and small errors in the position $(9.56 \pm 13.94 \mathrm{~m})$, respectively. The results show that glacier dynamics and ice-dam's formation respond to different time-scales; whilst in short-, intermediate-term (daily seasonal scales), the occurrence depends as much on the characteristics of the event as on the phase and intensity of the previous event. On the contrary, in long-term periods (scales greater than one year), low-frequency modulation of the ice flow velocity, caused by variations in air temperature, controls the periods with the formation of ice-dams and free of them.

Palabras clave: Glaciar Perito Moreno, oscilaciones frontales, dique de hielo, glaciar de calving, modelado numérico.

Key words: Perito Moreno Glacier, ice-front oscillations, ice-dam, freshwater calving glacier, numerical modelling.

Recibido: 10 de abril de 2019

Aceptado: 02 de julio de 2019

*Correspondencia: E. Lannutti, Instituto Argentino de Nivología, Glaciología y Ciencias Ambientales (IANIGLA)-Centro Científico Tecnológico (CCT), CONICET, Avda. Ruiz Leal s/n, Parque General San Martín, CP 5500 Mendoza, Argentina. Email: elannutti@ mendoza-conicet.gob.ar

\section{Introducción}

En la zona austral de Sudamérica, el Campo de Hielo Patagónico Sur (CHPS), representa una de las masas más grandes de hielo glaciar del hemisferio sur (Aniya et al., 1996). El CHPS se encuentra ubicado en los Andes patagónicos, en la frontera entre Argentina y Chile (Fig. 1), cubriendo una superficie de $13.000 \mathrm{~km}^{2}$, una longitud media de aproximadamente $30-40 \mathrm{~km}$ y una altitud media de $1191 \mathrm{~m}$ s.n.m. (Aniya et $a l ., 1996)$. En correspondencia con el entorno global, la gran mayoría de sus glaciares presentan retracciones frontales y adelgazamientos de sus masas de hielo (Rignot et al., 2003; Willis et al., 2012; Jaber, 2016; Solomina et al., 2016; Foresta et al., 2018; Richter et al., 2019). La retracción de los glaciares más importantes que integran el CHPS responden a procesos de desprendimiento de bloques de hielo en sus márgenes 


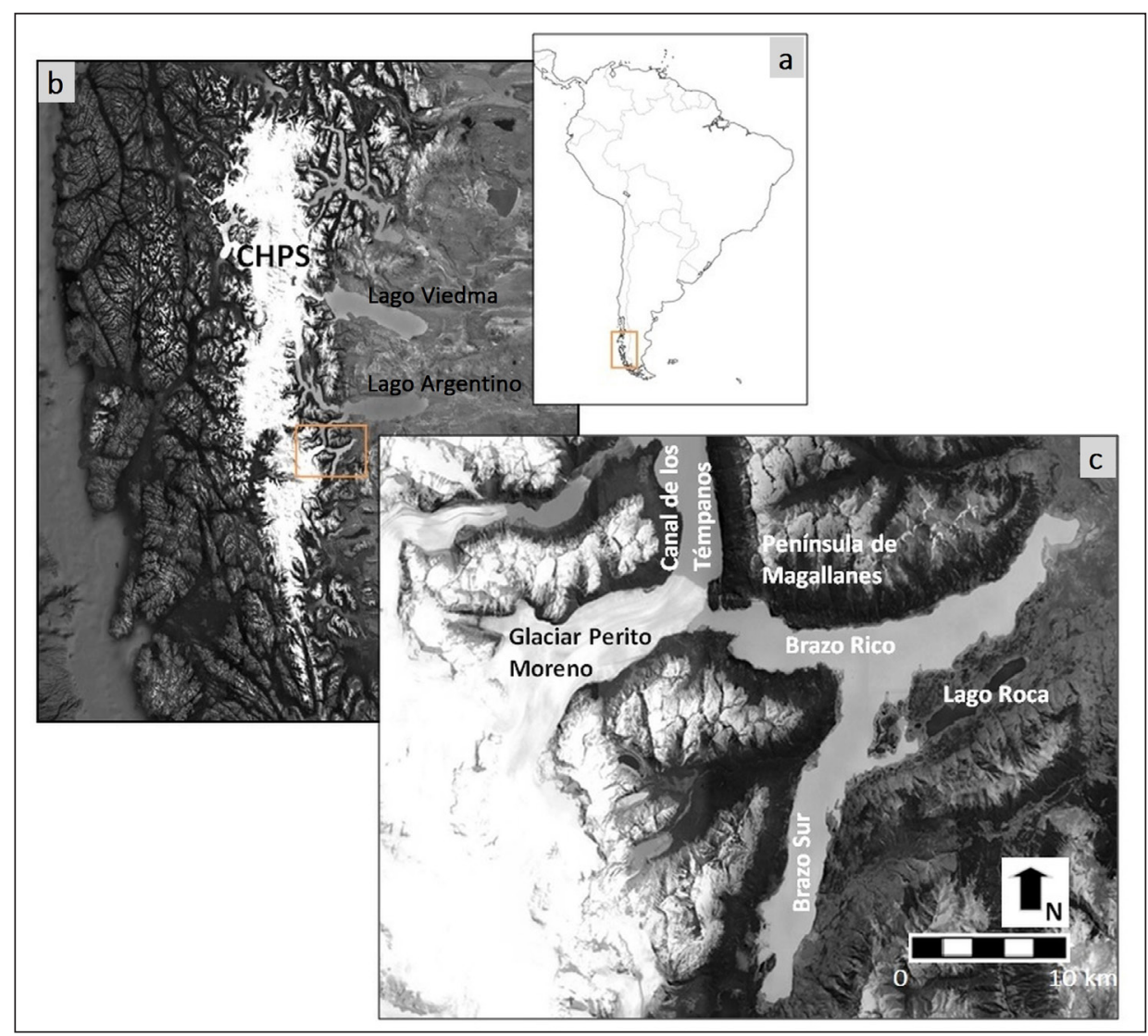

Figura 1. a) Mapa de Sudamérica donde se indica el área de estudio dentro de la provincia de Santa Cruz, Argentina. b) Imagen del Campo de Hielo Patagónico Sur y la localización del Lago Viedma, Lago Argentino y glaciar Perito Moreno. c) Imagen con la ubicación relativa del glaciar Perito Moreno, Península de Magallanes, Canal de los Témpanos, Brazo Rico, Brazo Sur y Lago Roca.

(calving) en contacto con lagos y fiordos. Cabe destacar que el proceso de calving cobra significancia cuando los glaciares terminan en lagos profundos (Cuffey y Paterson, 2010). Un ejemplo claro de este proceso puede evidenciarse en importantes glaciares como Upsala y Viedma, los cuales presentan grandes tasas de retracción frontal (Upsala: -272 m año-1 (1984-2011) (Sakakibara y Sugiyama, 2014); Viedma: -87,5 m año-1 (1976-2016) (Lo Vecchio et al., 2018) vinculadas con el calving producido por la interacción con sus lagos proglaciales (Lago Argentino y Viedma, respectivamente).

El Glaciar Perito Moreno (GPM) se encuentra ubicado en el CHPS $\left(50^{\circ} 29^{\prime} \mathrm{S} 73^{\circ} 03^{\prime} \mathrm{O}\right.$, Fig. 1a-b), presenta un área de $259 \mathrm{~km}^{2}$ (De Ángelis, 2014) con un espesor de 200-800 m a lo largo de la línea de flujo central (Sugiyama et al., 2011). El glaciar desciende por el valle con una pendiente media de aproximadamente $100 \mathrm{~m} \mathrm{~km}^{-1}$ (Pasquini y Depetris, 
2011) y divide el lago en Canal de los Témpanos (CT) y Brazo Rico (BR) (Fig. 1c). La altura de la parte terminal es de 50-80 m (Rott et al., 1998) y la profundidad media del lago es de 105 m y 64 m en el CT y BR, respectivamente (Stuefer, 1999). La velocidad superficial del flujo de hielo cambia con la altitud; por ejemplo: a $15 \mathrm{~km}$ del frente (1200 m s.n.m.) la velocidad es de $4 \mathrm{~m} \mathrm{día}^{-1}$ y de $2,5 \mathrm{~m} \mathrm{día}^{-1}$ a $2 \mathrm{~km}$ del frente (Minowa et al., 2017), mientras que el flujo de la parte terminal del glaciar se mueve a velocidades de 1,5 $\mathrm{m} \mathrm{día}^{-1}$ (Ciappa et al., 2010). El GPM es de base templada y su dinámica responde en mayor medida al desplazamiento basal que al desplazamiento por deformación (Stuefer, 1999; Sugiyama et al., 2011). Estudios sobre la zona basal indican que la velocidad del GPM está relacionada con la temperatura del aire, lo que implica que la presión basal del agua está controlada principalmente por la velocidad de producción del agua de fusión (Sugiyama et al., 2011). El GPM, al igual que muchos de los glaciares del CHPS, es afectado por procesos de calving, sin embargo, a diferencia de la gran mayoría de estos, el glaciar mantiene un espesor de hielo estable (Jaber, 2016; Malz et al., 2018) y en los últimos cien años su posición frontal no responde a retracciones sostenidas (Skvarca y Naruse, 1997; Stuefer, 1999; Minowa, 2017). Trabajos previos atribuyen esta estabilidad a su relativa amplia área de acumulación (Stuefer et al., 2007; Minowa et al., 2015) y a la topografía poco profunda cerca de la parte frontal del glaciar (Aniya, 1992; Skvarca y Naruse, 1997).

Haciendo un análisis más detallado de su estabilidad, se observa que desde principios de siglo XX, el frente del GPM presenta avances y retrocesos recurrentes a la Península de Magallanes (PM) (Fig. 1c) y su comportamiento responde a un ciclo oscilatorio estacional de avance y retracción (Sersic, 1988; Minowa et al., 2017; Lenzano et al., 2018). El ciclo de oscilación tiene amplitudes promedias de $\pm 60 \mathrm{~m}$, frecuencias anuales y fase de avance (junio-diciembre) y de retroceso (diciembre-abril) (Minowa et al., 2017). En algunos años, el semiperiodo de avance alcanza completamente la PM, formando un dique de hielo que represa el BR del Lago Argentino (LA) elevando su nivel de agua, en algunos casos, decenas de metros (Lenzano et al., 2018). Según los represamientos registrados, la columna de agua acumulada nunca ha sobrepasado la altura del frente de hielo de $80 \mathrm{~m}$ en la parte terminal del glaciar. Por lo tanto, el aumento progresivo de este nivel de agua, en la mayoría de los casos culmina con una ruptura abrupta del dique, produciéndose un volcado repentino del volumen de agua al LA que altera el sistema hídrico aguas abajo del GPM. Sersic (1988), Skvarca y Naruse (1997), Stuefer (1999), Minowa (2017) y Lenzano et al. (2018), entre otros, han analizado el comportamiento singular del GPM, sin embargo, aún no se ha explicado con precisión cuales son las causas y los procesos que controlan la dinámica del glaciar. En particular, existen tres trabajos que centran el estudio de la dinámica en el proceso oscilatorio estacional que muestra el GPM. Sersic (1988) propone un modelo matemático basado en leyes físicas, que calcula las oscilaciones del frente en forma analítica. El resultado del modelo deja en evidencia la relevancia que tiene la descarga de agua a través del dique del hielo en el control de la posición frontal. Si bien, su aporte ha sido sustancial, su análisis se centra en un modelo teórico-analítico carente de validación y datos medidos. Minowa (2017) relaciona principalmente la variación frontal estacional con las condiciones térmicas del lago proglacial, sin embargo, no 
propone un modelo o una teoría sólida que explique el comportamiento del GPM y los eventos de formación de diques de hielo a lo largo del tiempo. Recientemente, Lenzano et al. (2018), plantean un concepto de Avance-Cierre-Apertura-Retroceso (ACAR) basado en el análisis de Sersic (1988), que explica la oscilación a través de un sistema topográfico-hídrico-glaciar que establece un lazo de realimentación originado por la interacción del glaciar con la PM y LA. El glaciar en su proceso de avance hacia la PM, forma un canal que divide un sector del LA en el Canal de los Témpanos (CT) y el Brazo Rico (BR)-Brazo Sur (BS)-Lago Roca (LR) (Fig. 1c). Durante este proceso, el cuerpo de hielo forma un dique (completo o incompleto) que luego culmina en un vaciamiento (abrupto o moderado) del agua acumulada en el BR hacia el CT. Esto produce un nuevo retroceso, continuado de un posterior avance, estableciendo el ciclo oscilatorio anual de la posición frontal. En la actualidad, no existe un estudio específico que valide el ACAR.

Por otro lado, desde principios del siglo XX, los eventos de formación de diques de hielo producidos por el GPM muestran un complejo patrón temporal de ocurrencia, con periodos de 1, 2, 3, 4, 5, 16, 18 años (Liss, 1970; Aniya et al., 1992; Stuefer, 1999; Svarka y Naruse, 2005; Pasquini y Depetris, 2011; Lenzano et al., 2018). Esto indica que el estudio de la ocurrencia de los diques de hielo precisa de un análisis que tenga en cuenta diferentes escalas temporales con periodos de tiempo cortos-intermedios (escalas diarias-estacionales) y largos (escalas mayores a un año). Además, al parecer el cambio climático global está afectando a muchos de los procesos que controlan la dinámica de un glaciar en calving (Benn y Evans, 2014). En este tipo de glaciares en particular, la dinámica tiene una estrecha relación con el movimiento basal del hielo (Meier y Post, 1987), que depende sensiblemente de la temperatura del ambiente, la cual no solo tiene variaciones de corto e intermedio periodo, sino también de largos periodos. En este sentido, resulta relevante comprobar si las variaciones de largos periodos de temperatura del aire inciden en la dinámica del GPM y, en particular, si controlan los periodos de ocurrencia de formación de diques de hielo.

Este trabajo propone el desarrollo e implementación de un modelo teórico numérico computacional basado en: (i) las leyes que gobiernan el flujo de hielo en un glaciar donde la posición frontal del GPM estará definida por el resultado entre la velocidad del flujo frontal y la tasa de retracción (Cuffey y Paterson, 2010; Benn y Evans, 2014); (ii) un mecanismo de lazo de realimentación, fundamentado en la acumulación de energía potencial en el BR-BS-LR y la transformación a energía cinética de aumento de la velocidad de circulación del agua por el canal, que en definida interviene en la retracción del frente del glaciar (Lenzano et al., 2018). De esta forma, el modelo contribuye a la validación del concepto ACAR y al estudio y análisis de los diversos eventos de represamiento que ha registrado el GPM.

El Modelo Oscilatorio de Avance-Cierre-Apertura-Retracción (MO-ACAR) propuesto, plantea simular diariamente la oscilación de la posición frontal y la ocurrencia de la formación de diques de hielo durante un periodo de 24 años (1994-2018). Estos dos parámetros representan las variables de salida de simulación del modelo, el cual es alimentado por mediciones de niveles de los lagos, velocidades del flujo del glaciar, 
caudales, topografía, temperatura y registros temporales de represamiento y descarga de agua por el canal. Además, para mejorar y evaluar la precisión de las simulaciones, el MO-ACAR es validado mediante un proceso iterativo de optimización y calibración.

\section{Fundamentos teóricos}

\subsection{Posición frontal del glaciar}

La tasa de desplazamiento de la posición frontal de un glaciar en calving (dl/dt) está dada por

$$
d l / d t=U_{m}-\dot{a},
$$

donde $U_{m}$ es la velocidad del flujo de hielo frontal y $\dot{a}$ es la tasa de ablación frontal (Cuffey y Paterson, 2010; Minowa, 2017). De acuerdo al concepto ACAR propuesto por Lenzano et al. (2018), la tasa de ablación total del GPM está determinada por una tasa de retracción adicional. Esta tasa de retracción es función de la velocidad de descarga del agua que circula por el canal, producida por la diferencia de nivel del agua entre el BR y CT (Fig. 2). Por lo tanto, podemos definir que

$$
\begin{aligned}
& d l / d t=U_{m}-\left(\dot{a}+\dot{a}_{d w}\right)=U_{m}+\left(\dot{a}_{t}\right) \\
& \dot{a}_{d w}=f\left(v_{d w}(t)\right),
\end{aligned}
$$

Donde $\dot{a}_{t}$ es la tasa de ablación total, $\dot{a}_{d w}$ es la tasa de retracción producida por el proceso de descarga y $v_{d w}(t)$ es la velocidad del agua que circula por el canal.

La energía potencial (diferencia de nivel del agua entre BR y CT) y el caudal de descarga del CT $\left(Q_{\text {outl }}(t)\right)$ es representado por (Lenzano et al., 2018)

$$
\begin{aligned}
& h(t)=C T L(t)-B R L(t) \\
& Q_{\text {out } 1}(t)=-S(B R L(t)) \frac{d h(t)}{d t}+Q_{\text {in } 1}(t)
\end{aligned}
$$

Donde $h(t)$ es la diferencia en el nivel de los lagos, $C T L(t)$ y $B R L(t)$ son los niveles del Canal de los Témpanos y Brazo Rico, respectivamente. $S(B R L(t))$ es el área del Brazo Rico-Brazo Sur-Lago Roca (BR-BS-LR), la cual es función de $B R L(t)$ y $Q_{\text {inl }}(t)$ es el caudal de entrada al BR-BS-LR. 


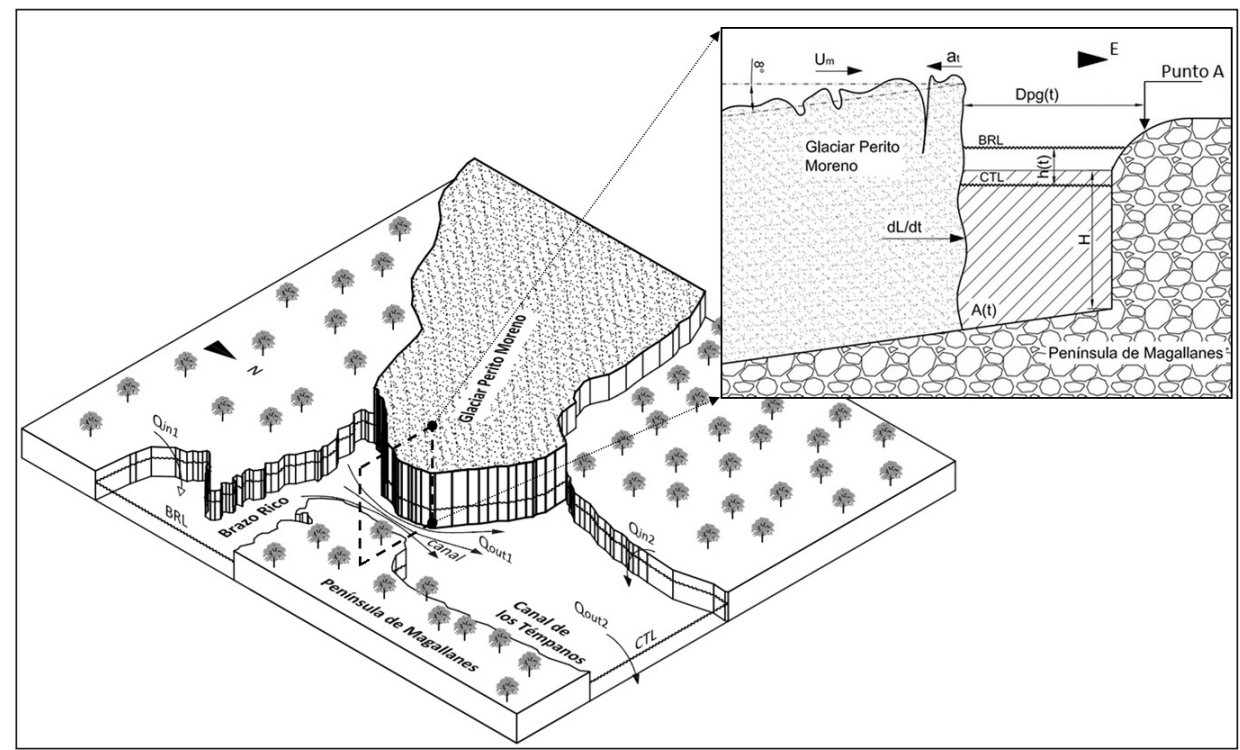

Figura 2. Esquema conceptual con las variables que intervienen en el modelo numérico desarrollado: $Q_{i n 1}$ (caudal de entrada al Brazo Rico-Brazo Sur-Lago Roca), $Q_{i n 2}$, (caudal de entrada del Lago Argentino), $Q_{\text {outl }}$ (caudal de salida del Brazo Rico hacia el Canal de los Témpanos), $Q_{\text {out }}$ (caudal de salida del Lago Argentino), BRL (nivel del Brazo Rico), CTL (nivel del Canal de los Témpanos), $U_{m}$ (velocidad del flujo de hielo frontal), $a_{t}$ (tasa de ablación total), $h(t)$ (diferencia en el nivel de los lagos), $H$ (profundidad media del canal), $A(t)$ (área de descarga), $d L$ / dt (tasa de desplazamiento de la posición frontal) y Dpg (t) (distancia del frente del glaciar a la Península de Magallanes medida desde el punto A).

Al mismo tiempo, el caudal de descarga en el canal está dado por

$$
Q_{\text {out } 1}(t)=\frac{d V}{d t}=\frac{d x}{d t} A(t)=v_{d w}(t) A\left(\text { topografía }, D_{p g}(t)\right),
$$

Donde $V$ es el volumen de agua, $(d x / d t)$ es la velocidad del agua $\left(v_{d w}(t)\right)$ y $A$ es el área de descarga, que es función de la topografía del canal y de la distancia de la Península de Magallanes al frente del glaciar $\left(D_{p g}(t)\right)$ (Fig. 2).

\subsection{Ocurrencia de formación de diques de hielo}

Un evento de formación de dique de hielo ocurre cuando la velocidad del flujo frontal $\left(U_{m}\right)$ supera la tasa de ablación total $\left(\dot{a}_{t}\right)$, de tal manera que el frente del GPM avanza hasta alcanzar la PM formando un represamiento entre el BR y CT. Por lo tanto, la variable "ocurrencia de formación de diques de hielo" queda definida para los periodos donde la distancia del frente del glaciar tiende a cero. 


$$
\left\{\begin{array}{l}
D_{p g}(t) \rightarrow 0 \text { formación de dique de hielo } \\
D_{p g}(t)>0 \quad \text { sin formación de dique de hielo }
\end{array}\right.
$$

Durante estos procesos, el área efectiva de descarga $A(t) \rightarrow 0$, por lo tanto, la velocidad del agua que fluye por el canal $v_{d w}(t)$ y en definitiva $\overrightarrow{a_{d w}}$ tienden a cero. De este modo, $\dot{a}_{t}$ disminuye por la reducción de la tasa de calving, así como también, por la desaparición del efecto de $a_{d w}^{*}$ favoreciendo así a la formación y persistencia del represamiento. El tiempo de permanencia o resistencia del dique, depende de $Q_{\text {in1 }}(t)$ y del balance entre $Q_{\text {in2 }}(t)$ y $Q_{\text {out } 2}(t)$, pero en mayor medida, de la masa de la estructura de hielo formada entre el BR y el CT la cual, a su vez, depende de la potencia de avance del glaciar hacia la PM para un determinado evento. Es por ello, que la diferencia de nivel entre los lagos y las rupturas alcanzan distintos niveles e intensidades dependiendo de la robustez del dique formado (Lenzano et al., 2018).

Los eventos de descarga y la subsiguiente ruptura del dique de hielo se inician cuando el agua comienza a encontrar su camino bajo la presa de hielo y el flujo se localiza, ya sea en un solo canal, o en un conjunto de canales pequeños. La energía disipada por el agua que fluye, derrite el hielo circundante, resultando en la ampliación del canal (Walder y Costa, 1996) provocando que $A\left(t_{d d}\right)>0$ para cada registro temporal de descarga $\left(t_{d d}\right)$. Cabe destacar, que los eventos de descarga y ruptura son dos procesos distintos. El evento de ruptura queda definido cuando se produce el colapso del "puente" de hielo formado entre el frente del glaciar y PM, el cual sucede después del inicio del proceso de descarga de agua por el canal (Lenzano et al., 2018). En cambio, el evento de descarga está asociado con la interrupción de la acumulación de agua en el BR debido al comienzo de la infiltración en la estructura del dique de hielo que supera el caudal de entrada en el BR (Lenzano et al., 2018). Por lo tanto, teniendo en cuenta el comportamiento general del GPM, podemos definir que el área de descarga está dada por

$$
A(t)=\left\{\begin{array}{l}
\delta A \quad t=t_{d d} \\
A\left(\text { topografía, } D_{p g}(t)\right) \text { para los demás casos }
\end{array}\right.
$$

Donde $d A$ es un área infinitesimal de apertura del canal provocado por el comienzo de la filtración del agua en el dique de hielo. 


\section{Modelo MO-ACAR}

El objetivo del MO-ACAR consiste en simular diariamente la distancia del frente del glaciar a la PM $\left(D_{p g}(t)\right)$ y la ocurrencia de formación de diques de hielo $\left(I D_{o}(t)\right)$ para un periodo comprendido entre enero de 1994 a agosto del 2018. El diagrama de flujo de la Figura 3 muestra el procedimiento para construir el modelo numérico computacional MO-ACAR conformado por las variables de entrada, el sistema, las variables de salida de simulación y los procesos de calibración y validación del modelo. Las variables de entrada están compuestas por un conjunto de parámetros medidos, donde en algunos casos tienen etapas de pre-procesamiento para adecuar los datos antes de ingresar al sistema (ej. procesos de filtrado y ajuste de curvas). A partir de estas variables de entrada, el sistema utiliza las ecuaciones abordadas en la sección 2 para calcular las variables de salidas de simulación $\left(D_{p g}(t)\right.$ y $\left.I D_{o}(t)\right)$. Para calibrar y posteriormente validar el MOACAR, las salidas del modelo simuladas son comparadas con datos medidos de posición frontal del glaciar y datos temporales de ocurrencia de formación de diques de hielo $\left(D_{p g}(t)_{m}\right.$ y $\left.I D_{o}(t)_{m}\right)$ en un proceso iterativo de optimización del modelo. Como muestra el

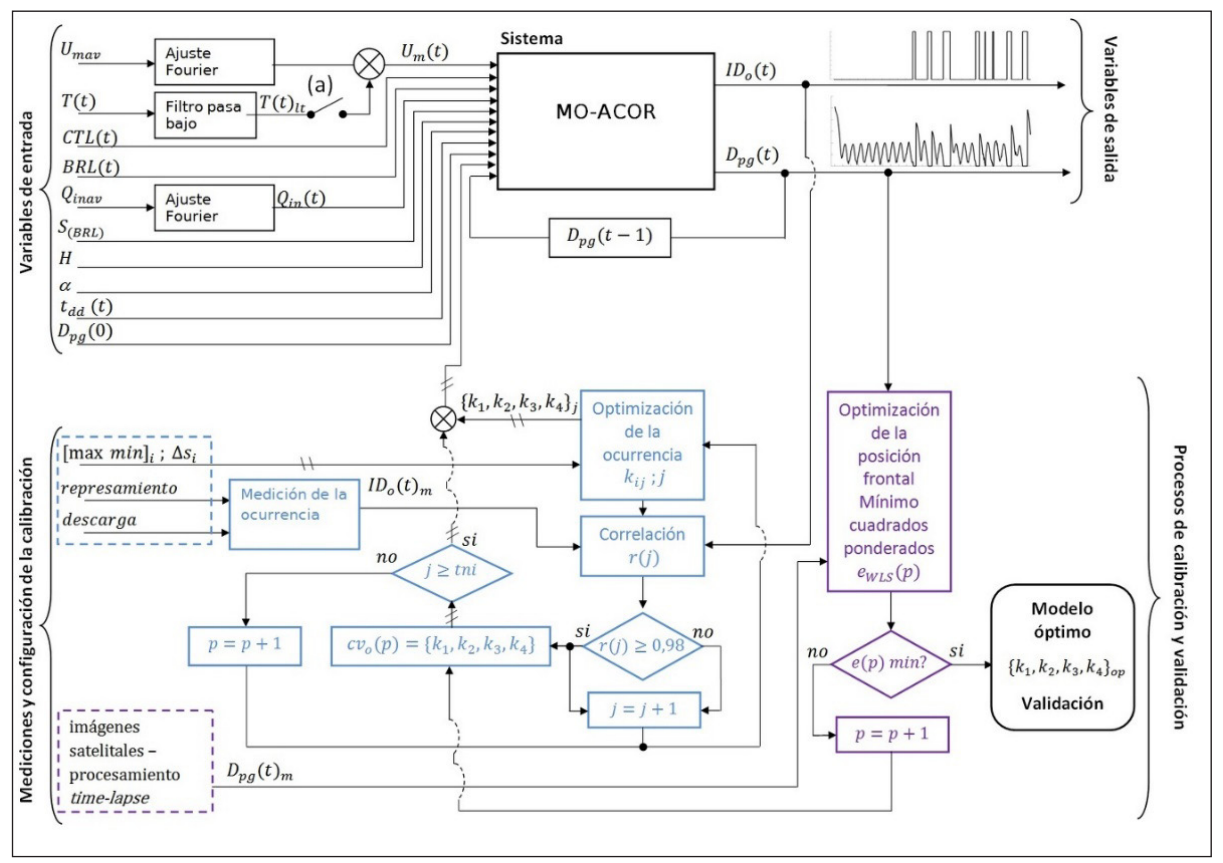

Figura 3. Diagrama de flujo del modelo MO-ACAR propuesto, donde se detallan en color negro las variables de entrada, la etapa de pre-procesamiento, el sistema y sus variables de salida. Nótese que los procesos de optimización del modelo están indicados con diferentes colores en la parte inferior del diagrama. En primer lugar, la optimización de la ocurrencia de formación de diques de hielo (color azul), y luego, la optimización de la distancia del frente del GPM a la Península de Magallanes (color violeta). 
diagrama de flujo, la calibración está compuesta por dos procesos: uno de optimización de ocurrencia de eventos (color azul) y otro de optimización de la distancia del frente del glaciar a la PM (color violeta). El objetivo de estos procesos es determinar y ajustar los parámetros de calibración hasta obtener un modelo óptimo que simule de forma representativa y precisa el ACAR (ver sección 4).

El diseño e implementación de todos los procesos que integran MO-ACAR fue realizado mediante la herramienta de cálculo matemático Matlab.

\subsection{Variables de entrada}

La velocidad del flujo de hielo del frente del glaciar $U_{m}$ de la ecuación (1) y (2) presenta una variación sinusoidal estacional (Stuefer, 1999; Minowa, 2017; Lenzano et al., 2018). Dado el comportamiento estacional de la señal, se estimó la velocidad del flujo diaria para el periodo 1994-2018 mediante el método Fourier de ajuste de curvas (Fig. 3) tomando la media mensual de la variación anual de la velocidad frontal del glaciar $\left(U_{m a v}\right)$, medida por Minowa (2017). Se utilizó este método de ajuste, debido a que presenta óptimas soluciones para variables del tipo sinusoidal como la señal propuesta. Este método ajusta la función $f(t)$ mediante la siguiente ecuación (Abuelma'atti, 1993).

$$
f(t)=a_{0}+\sum_{q=1}^{\infty} a_{q} \operatorname{sen}\left(b_{q} t+\theta_{q}\right)
$$

donde los coeficientes $a_{q}, b_{q}$ y $\theta_{q}$ son las amplitudes, periodos y fases de las funciones sinusoidales, respetivamente.

La temperatura del aire $T(t)$ se obtuvo mediante las mediciones realizadas en el GPM por Stuefer (1999) y Minowa (2017) para el periodo comprendido entre 1996 y 2014. Este parámetro permitirá modular la velocidad frontal del glaciar $U_{m}$ mediante el switch (a) de la Figura 3, con el objetivo de calibrar un modelo con variaciones temporales largas de temperatura de aire y libres de ellas (para más detalle ver sección 4.3).

Los niveles de agua diarios $C T L(t)$ y $B R L(t)$ (Fig. 2) para el periodo 1994-2018 se obtuvieron de las series temporales de escalas limnimétricas de las alturas de agua del Lago Argentino y Brazo Rico, proporcionadas por la Subsecretaría de Recursos Hídricos de la Nación Argentina.

La variación anual media del caudal de entrada $\left(\mathrm{Q}_{\text {inav }}\right)$ y el área $S(B R L(t))$ de la ecuación (5) se estimaron utilizando la metodología propuesta en Lenzano et al. (2018). Para establecer el caudal de entrada diario $\left(\mathrm{Q}_{\text {inl }}(\mathrm{t})\right)$, para el periodo de 24 años, se ajustó $\mathrm{Q}_{\text {inav }}$ mediante el método Fourier de ajuste de curvas (ecuación 11), dada su variación estacional sinusoidal.

Para calcular el área de descarga efectiva diaria de la ecuación (6) se precisa definir la topografía del canal a través de su profundidad media $H$ y la pendiente del 
lecho $\alpha$ (ver sección 3.2). La profundidad del canal $H=70 \mathrm{~m}$ se determinó a partir de los datos batimétricos medidos por Stuefer (1999), Minowa (2017) y Sugiyama et al. (2016), tomando la profundidad media en el sector más próximo a la zona de contacto del frente del glaciar con la PM entre el BR y CT. Por otro lado, debido a que el flujo de hielo del glaciar presenta un comportamiento plástico, la pendiente de la base del canal puede aproximarse a la pendiente de la parte alta del glaciar (Benn y Evans, 2014) (Fig. 2). A partir del sistema de adquisición de imágenes y el procesamiento estereoscópico fotogramétrico utilizado por Lenzano et al. (2018), se estimó la pendiente del canal $\alpha=8^{\circ}$ midiendo el ángulo de inclinación horizontal de la parte frontal del glaciar. La pendiente es ascendente en la parte terminal debido a que el frente se monta sobre la PM, en su proceso de aproximación.

El tiempo de descarga $\left(t_{d d}\right)$, para el periodo comprendido entre 1994 y 2018, se definió a partir del resumen de eventos de formación de diques de hielo de Lenzano et al. (2018), al cual se le adicionaron los dos últimos eventos registrados (2016 y 2018).

Por último, al correr el modelo en su fase de inicio, se decidió alejar el frente del glaciar de la PM $\left(D_{p g}(0)=250 \mathrm{~m}\right)$ para que la simulación comience libre de represamiento y sin intervención de la tasa de retracción $\left(a_{d w}^{\cdot}\right)$, producida por el proceso de descarga.

\subsection{Sistema y variables de salida del modelo}

Como indica el diagrama de flujo de la Figura 3, las dos variables de salida del MO-ACAR son $D_{p g}(t)$ (distancia de la Península de Magallanes al frente del glaciar) y $I D_{o}(t)$ (ocurrencia de formación de diques de hielo). Ambos parámetros quedan definidos a partir de la tasa de desplazamiento de la posición frontal de las ecuaciones (1) y (2). Pasando las ecuaciones a tiempo discreto, para un $\Delta \mathrm{t}=1$ (diario), $\mathrm{y}$, además, adecuando las variables de las ecuación (2) nos queda

$$
D_{p g}(t)=D_{p g}(t-1)-U_{m}(t)+\left(\dot{a}(t)+\dot{a}_{d w}(\mathrm{t})\right)
$$

Cabe destacar que debido a los diferentes niveles que alcanza el lago, la distancia $D_{p g}(t)$ es medida desde un punto fijo en el interior de la península (punto A (50²8’26.13”'S 7302'09.50”O), ver Fig. 2) y no desde el límite del agua con la roca.

Siguiendo la misma metodología para calcular $U_{m}(t)$ (sección 3.1), la tasa de ablación frontal diaria para el periodo 1994-2018 $(\dot{a}(t))$ puede determinarse a partir de la variación anual de la tasa de ablación frontal estimada por Minowa (2017). No obstante, este parámetro contiene la ablación total $\dot{a}_{t}(t)$ experimentada en el frente del glaciar y no está disociado el proceso de ablación producido por el caudal de descarga de agua en el canal. En este sentido, podemos definir una tasa de ablación diaria $\dot{a}(t)$ gobernada por variaciones estacionales anuales y una tasa de retracción producida por el proceso de descarga. Por otro lado, dado que la velocid ad de circulación de agua por el canal queda definida por la transformación de energía potencial a cinética, es de esperar que la relación entre $a_{d w}^{\cdot}$ y $v_{d w}$ no sea lineal y presente un comportamiento potencial. Por lo tanto, a partir de las ecuaciones (3) y (2) podemos definir que 


$$
\left\{\begin{array}{l}
\dot{a}_{d w}(t)=k_{1} v_{d w}(t)^{k_{2}} \\
\dot{a}(t)=k_{3}+k_{4} \sin \left(2 \pi f_{a} t+\theta_{a}\right), \text { para } k_{3} \geq k_{4}
\end{array}\right.
$$

Donde $k_{1}$ y $k_{2}$ son el coeficiente lineal y el exponente de la función propuesta, respectivamente. $f_{a}$ es la frecuencia, la cual presenta un periodo anual y $\theta_{a}$ es la fase del semi-periodo positivo (noviembre-abril) y semi-periodo negativo (mayo-octubre) (Minowa, 2017). $k_{3}$ y $k_{4}$ son el término medio y la amplitud de $a(t)$ y están restringidos a $k_{3} \geq k_{4}$ ya que $a(t)$ no puede tomar valores negativos. Los cuatro coeficientes $k_{i}$ de las ecuaciones (13) y (14) son parámetros desconocidos y corresponden a los parámetros de calibración del modelo (ver sección 4).

Por lo tanto, la distancia del frente del glaciar a la PM está dada por

$$
D_{p g}(t)=D_{p g}(t-1)-U_{m}(t)+\left(k_{3}+k_{4} \sin \left(2 \pi \mathrm{f}_{\alpha} t+\theta_{a}\right)+k_{1} v_{d w}(t) k_{2}\right)
$$

de (6) y tomando (5) podemos definir a $v_{d w}(t)$ como

$$
v_{d w}(t)=\frac{Q_{o u t 1}(t)}{A(t)}
$$

Donde $Q_{\text {out } 1}(t)$, para tiempo discreto $\Delta \mathrm{t}=1$ (diario), nos queda

$$
Q_{\text {out } 1}(t)=-S(B R L(t))(h(t)-h(t-1))+Q_{\text {in } 1}(t)
$$

El área de descarga efectiva diaria $A(t)$ queda definida por la topografía del canal. En la Figura 2 se muestra un esquema con la geometría del canal propuesta para el modelo, la cual está definida mediante un área rectangular con una pendiente ascendente hacia la PM. Por lo tanto, el área de descarga propuesta está dada por

$$
A(t)=H D_{p g}(t)+\frac{D_{p g}(t)^{2} \tan \alpha}{2}
$$

donde $H$ y $\alpha$ son la profundidad media y pendiente de la base del canal, respectivamente (ver sección 3.1). Pasando a tiempo discreto $\Delta \mathrm{t}=1$ (diario) y a partir de (9), (10) y (18) podemos definir que 


$$
A(t)=\left\{\begin{array}{l}
\Delta A_{\Delta t} \quad t=t_{d d} \\
H D_{p g}(t-1)+\frac{D_{p g}(t-1)^{2} \tan \alpha}{2} \text { para los demás casos }
\end{array}\right.
$$

donde $\Delta A_{\Delta t}$ es el área de apertura del canal provocado por el comienzo de la filtración del agua en el dique de hielo. $\Delta A_{\Delta t}=A\left(t_{d d}\right)=150 \mathrm{~m}^{2}$, se definió tomando un promedio entre el cambio de área generado durante el primer día de descarga de los hidrogramas de descargas calculados en Skvarca y Naruse (2005) y Lenzano et al. (2018).

Por otro lado, la variable de salida de ocurrencia de formación de diques de hielo, se definió como una variable binaria que toma el valor uno durante un proceso de represamiento y cero cuando no hay evento. De (7) y (8), podemos entonces definir

$$
I D_{o}(t)=\left\{\begin{array}{cc}
1 & D_{p g}(t)=0 \\
0 & D_{p g}(t)>0
\end{array}\right.
$$

\section{Calibración y validación del modelo}

La calibración y validación de modelos son el procedimiento principal para evaluar los modelos computacionales y para hacer coincidir las observaciones físicas con las simulaciones (Wu et al., 2015). La calibración es un proceso iterativo de optimización que compara el modelo con el sistema real, hasta que el modelo es aceptado o validado. Los parámetros de calibración son aquellas variables del modelo típicamente poco identificables o sin información (Dahabreh et al., 2017). Como muestra la parte inferior del diagrama de flujo de la Figura 3 la calibración del MO-ACAR consiste en un proceso iterativo de comparación de las variables de salida simuladas $\left(D_{p g}(t)\right.$ y $\left.I D_{o}(t)\right)$ con datos medidos de posición frontal del glaciar y ocurrencia de formación de diques de hielo $\left(D_{p g}(t)_{m}\right.$ y $\left.I D_{o}(t)_{m}\right)$. Por lo tanto, el proceso de calibración ayudará a limitar la incertidumbre en los valores de los parámetros de calibración $k_{i}$ de la ecuación (15), hasta alcanzar un desempeño óptimo de las salidas simuladas que valide el MO-ACAR.

Dado que este proceso requiere el ajuste simultáneo de dos variables de salida, resulta necesario aplicar un método de optimización multi-objetivo. No obstante, las variables de entrada $C T L(t)$ y $B R L(t)$ son mediciones de niveles del agua que contemplan la interacción del glaciar con la PM en los procesos de represamiento. Por lo tanto, para que estos niveles sean variables de entradas válidas, en primera instancia, es necesario que el modelo garantice la simulación precisa de la variable de ocurrencia temporal de estos eventos. En este sentido, el proceso de simulación se dividió en dos métodos de optimización, con prioridad a la optimización de la ocurrencia de formación de diques de 
hielo. De este modo, se realizó una primera calibración del modelo (proceso azul, Fig. 3) por medio de un proceso de optimización capaz de determinar un conjunto de coeficientes $k_{i}$ candidatos que maximicen una función de correlación entre $I D_{o}(t)$ y $I D_{o}(t)_{m}$. Luego, a partir del conjunto de candidatos obtenidos en el proceso previo, se realizó una segunda calibración (proceso violeta, Fig. 3) que minimice el error de distancia entre $D_{p g}(t)$ y $D_{p g}(t)$ ${ }_{m}$ para garantizar que el modelo simule la posición frontal del glaciar con precisión. Si el MO-ACAR calibrado responde dentro de un error de tolerancia preestablecido, el modelo puede ser validado.

Mediante esta metodología basada en dos procesos de optimización, se calibró en primera instancia, un modelo libre de variaciones de largos periodos temporales, y luego, con variaciones de largos periodos de la temperatura del aire para comprobar si esta variable incide en la dinámica del GPM (ver sección 4.3).

\subsection{Proceso de calibración de la ocurrencia de diques de hielo}

En el diagrama de flujo de la Figura 3, se muestra el primer proceso de calibración. Para generar las mediciones de ocurrencia de diques de hielo binaria $I D_{o}(t)_{m}$ se tomaron los datos del resumen de los eventos de represamiento de Lenzano et al. (2018) y nuevos datos estimados para los eventos 2016 y 2018, aplicando el mismo procedimiento que los autores utilizaron. Para un determinado dique de hielo $n$, con $1 \leq \mathrm{n} \leq 8$, correspondiente a los eventos 2004, 2006, 2008, 2012, 2013a, 2013b, 2016 y 2018 nos queda

$$
I D_{o}(t)_{m}= \begin{cases}1 & \text { Datos de represamiento }_{n} \leq t \leq \text { Datos de descarga }_{n} \\ 0 & \text { para los demás casos }\end{cases}
$$

Para el proceso de optimización se aplicó un método de búsqueda univariante secuencial a lo largo de un conjunto fijo de direcciones, el cual resulta la técnica de búsqueda multivariable más utilizada y sencilla de implementar. El método se basa en la variación de cada coeficiente $k_{i}$ entre dos umbrales preestablecidos [min, max] en pasos $\Delta s$, dejando los restantes 3 coeficientes $k_{i}$ constantes para cada iteración $j$. Como muestra la Figura 3, en cada iteración se calcula el coeficiente de correlación de Pearson $r$ entre $I D_{o}(t)$ y $I D_{o}(t)_{m}$ en búsqueda de un conjunto de candidatos óptimos $c v_{o}(p)=\left\{k_{1}, k_{2}, k_{3}, k_{4}\right\}$ que alcancen valores de $r(j) \geq 0,98$. Cabe destacar, que el valor de correlación de 0,98 fue elegido para garantizar que el modelo MO-ACAR simule los 8 eventos $(n)$ ocurridos en el periodo de estudio. El proceso termina cuando $j$ alcanza el número total de iteraciones (tni) que depende de los umbrales y pasos prefijados. El conjunto de umbrales y pasos asignados para $k_{i}$ y sus correspondientes números de iteraciones se detallan en la Tabla 1. Los umbrales máximos fijados para $k_{3}$ y $k_{4}$, se determinaron a partir de la ecuación (2), considerando siempre que los valores de $\dot{a}(t)$ resultarán menores que la variación anual de la tasa de ablación frontal $\dot{a}_{t}(t)$ calculada en Minowa et al. (2017) y los umbrales mínimos se hicieron iguales al paso 
Tabla 1. Listado con los parámetros y coeficientes $\left(k_{1}, k_{2}, k_{3}, k_{4}\right)$, donde se detallan los umbrales mínimos y máximos y el paso asignados. Además, se detalla la cantidad de iteraciones demandadas para cada coeficiente y las totales del proceso de calibración.

\begin{tabular}{|c|c|c|c|c|}
\hline $\begin{array}{l}\text { Coeficiente } \\
\text { Parámetro }\end{array}$ & Descripción & Umbral & $\operatorname{Paso} \Delta s$ & $\begin{array}{l}\text { Cantidad de } \\
\text { iteraciones }\end{array}$ \\
\hline$v_{d w}^{k_{1}}(t)$ & $\begin{array}{c}\text { Coeficiente } \\
\text { lineal }\end{array}$ & {$[0,0001 ; 0,001]$} & 0,0000001 & 9001 \\
\hline$v_{d w}^{k_{2}}(t)$ & Exponente & {$[1 ; 2]$} & 0,01 & 101 \\
\hline $\begin{array}{c}k_{3} \\
\dot{a}(t)\end{array}$ & Término medio & {$[0,1 ; 1,5]$} & 0,1 & \multirow{2}{*}{$\sum_{j}^{15} j=120$} \\
\hline $\begin{array}{c}k_{4} \\
\dot{a}(t)\end{array}$ & Amplitud & {$[0,1 ; 1,5]$} & 0,1 & \\
\hline & & & & $\begin{array}{c}\text { Total de iteraciones } \\
109 \mathrm{e} 6\end{array}$ \\
\hline
\end{tabular}

$\Delta s$. El coeficiente $k_{2}$ puede estar comprendido entre un comportamiento lineal $\left(k_{2}=\right.$ 1) y uno cuadrático $\left(k_{2}=2\right)$ (ver ecuación 13). El $k_{1}$ (coeficiente lineal de $v_{d w}(t)$ ), fue definido entre un umbral máximo para un $k_{2}$ mínimo $\left(\left(k_{2}=1\right)\right.$ y un umbral mínimo para un $k_{2}$ máximo $\left(k_{2}=2\right)$ que no alejen drásticamente el frente del glaciar de la PM. Dado que este coeficiente presenta el menor grado de certeza, es el que mayor umbral y menor $\Delta s$ relativos le fue asignado, por consiguiente, es el que mayor número de iteraciones demanda (ver Tabla 1). Los pasos $\Delta s$ se definieron a partir de una solución de compromiso entre costo computacional y eficacia en la detección de candidatos $c v_{o}$. En este sentido, un $\Delta s$ alto podría condicionar la detección de candidatos que alcancen un $r(j) \geq 0,98$, en cambio, un $\Delta s$ bajo, mejora este aspecto a costa de un aumento en los tiempos de procesamiento. Los $\Delta s$ para $k_{3}$ y $k_{4}$ son los más altos en forma relativa dado que la respuesta del modelo presenta más sensibilidad a las variaciones de $v_{d w}(t)$ que a las de $\dot{a}(t)$, por lo tanto $k_{1}$ y $k_{2}$ precisan de un ajuste más fino.

Como muestra la Tabla 1, la desventaja de utilizar búsquedas univariantes secuenciales es su baja eficiencia, dado que en la mayoría de las aplicaciones se requiere de un número elevado de iteraciones para alcanzar razonables niveles de precisión. Existen otros métodos multivariantes de optimización de mayor eficiencia (ej. Powell, Simplex Nelder-Meed, Random directions searching, entre otros), sin embargo, como en el proceso de búsqueda el $k_{1}$ demanda el 97,6 \% de las iteraciones (ver Tabla 1) y tiene un comportamiento unimodal, una óptima solución es aplicar el método univariado Fibonacci de eliminación de intervalos sobre el coeficiente $k_{1} \mathrm{y}$ mantener búsquedas univariantes secuenciales para determinar $k_{2}, k_{3} \mathrm{y} k_{4}$. 
El método Fibonacci se puede utilizar para encontrar el mínimo o máximo de una función de una variable, incluso si la función no es continua (Rao, 2009). Esta técnica es un método de búsqueda dentro de una matriz ordenada que utiliza un algoritmo de dividir y conquistar que reduce las posibles ubicaciones con la ayuda de los números de Fibonacci (Ferguson, 1960). Se optó por este método porque es la mejor técnica tradicional para encontrar el punto óptimo de una función unimodal ya que es el método de eliminación más eficiente para reducir el intervalo de incertidumbre y el que menos número de experimentos para una precisión especificada requieren (Subasi et al., 2004; Rao, 2009). Tomando los umbrales y una resolución igual a los pasos $\Delta s$ para $k_{1}$ de la tabla 1, se corrió el método de Fibonacci para encontrar un máximo de correlación para cada conjunto de umbrales y pasos de $k_{2}, k_{3} y k_{4}$. De esta forma, se obtuvo 121.020 (101 x 120) máximos de correlación para cada $k_{2}, k_{3} y k_{4}$ asignado. La ventaja de mantener búsquedas univariantes secuenciales sobre los últimos 3 parámetros es que se puede hacer un análisis del comportamiento de los valores de correlación en función de estos parámetros de calibración (ver sección 5.2).

\subsection{Proceso de calibración de la posición frontal}

La Figura 3 muestra el segundo proceso de calibración. $D_{p g}(t)_{m}$ se midió mediante un análisis de imágenes satelitales y un procesamiento estereoscópico fotogramétrico aplicado a imágenes Landsat 5, 7 y 8 ortorectificadas de la zona UTM 18S y datum WGS 84, cuya resolución espacial es de 15 y 30 metros por pixel. A partir de 29 imágenes satelitales libres de nubes, adquiridas entre 1994 y 2018, se midieron cambios en la posición del frente de hielo delineada mediante observación visual utilizando el sistema de información geográfica multiplataforma de código abierto QuantumGIS (www.qgis.com). Además, se determinó la posición frontal diaria del glaciar para el periodo Abril-2012 a Abril-2013 medidas por Lenzano et al. (2018) a partir del procesamiento fotogramétrico de imágenes obtenidas de fotografías timelapse. El sistema de adquisición de imágenes estereoscópicas está ubicado a menos de $2 \mathrm{~km}$ de la zona de contacto del glaciar con la PM y está conformado por una cámara CANON EOS Mark II DSLR con tamaño de pixel de 7,2 $\mu \mathrm{m}$ y distancia focal de $50 \mathrm{~mm}$ y una cámara NIKON D3 con tamaño de pixel de $8,5 \mu \mathrm{m}$ y distancia focal de $35 \mathrm{~mm}$ formando una base fotogramétrica de $165 \mathrm{~m}$. En total se obtuvieron 29 puntos del análisis de imágenes satelitales y 352 del procesamiento fotogramétrico time-lapse para el periodo total de estudio.

Como indica el diagrama de flujo de la Figura 3, tomando el conjunto de vectores candidatos calculados en el primer proceso de calibración, se simuló la posición frontal del glaciar para cada $c v_{o}(p)=\left\{k_{1}, k_{2}, k_{3}, k_{4}\right\}$ y se comparó con las mediciones en busca del mejor candidato que minimice el error cuadrático medio entre $D_{p g}(t)_{m}$ y $D_{p g}(t)$. Dado que $D_{p g}(t)_{m}$ se determinó a partir de mediciones con diferentes precisiones, el cálculo del error $\left(e_{W L S}(\mathrm{p})\right)$ fue estimado a partir de cálculos de mínimos cuadrados ponderados (Weighted Least-Squares WLS) (Mandel, 1964), tomando precisiones de 15 m, 30 m y 0,5 m para imágenes Landsat 7 y 8, Landsat 5 y procesamiento time-lapse, respectivamente. 


\subsection{Calibración del modelo con variaciones de temperatura del aire}

Jansson et al. (2003) establecen que el comportamiento de los glaciares está gobernado por diversos procesos que actúan con diferentes escalas temporales (periodos cortos, intermedios y largos). Hasta aquí, el modelo MO-ACAR está regido fundamentalmente por variaciones cortas (escalas temporales diarias) e intermedias (escalas temporales mensuales a estacionales). Por ejemplo, dos variables de entrada relevantes para el modelo $\left(U_{m}(t)\right.$ y $\left.\mathrm{Q}_{\text {in1 }}(t)\right)$ se estimaron a partir de la media mensual de la variación anual de la velocidad frontal del glaciar $\left(U_{\text {mav }}\right)$ y de la variación anual media del caudal de entrada $\left(\mathrm{Q}_{\text {inav }}\right)$ (ver sección 3.1). Este proceso elimina toda componente inferior a la frecuencia anual, al extender $U_{\text {mav }}$ y $\mathrm{Q}_{\text {inav }}$ anualmente durante los 24 años. Por lo tanto, a lo largo del periodo de simulación (1994-2018), tanto el sistema como la mayoría de las variables de entrada no tienen en cuenta variaciones de largos periodos (escalas temporales de años a centurias). Existe una variedad de procesos que gobiernan el comportamiento de un glaciar (ej. almacenamiento y liberación de nieve y agua, hidrología basal, mecánica del flujo de hielo, acumulación, ablación, derretimiento, drenaje, drenaje de glaciares represados, etc.) y, a su vez, parámetros con variaciones temporales de largos periodos que controlan estos procesos (ej. precipitación, topología, cambio climático, entre otras) (Cuffey y Paterson, 2010; Benn y Evans, 2014). Nótese que en el caso del GPM, la hidrología basal y la temperatura del aire presentan un importante rol en la dinámica de este glaciar (Sugiyama et al., 2011). Como establecen Meier y Post (1987), la dinámica de los glaciares de calving tiene una estrecha relación con la velocidad basal, la cual depende de las condiciones climáticas. Sugiyama et al. (2011) demuestran que el desplazamiento del GPM es modulado por la presión del agua bajo la influencia de los cambios del ingreso de agua de fusión. De esta manera la velocidad del hielo tiene una fuerte correlación con la temperatura del aire, la cual varía $\pm 0,053 \mathrm{~m}$ día $^{-1}$ para un cambio de temperatura de $\pm 1 \mathrm{C}^{\mathrm{o}}$. En este sentido, resulta relevante comprobar si, específicamente, las variaciones temporales de largos periodos de la temperatura del aire tienen un rol importante en la dinámica del GPM y si controlan los periodos de ocurrencia de formación de diques de hielo, a través de las variaciones en la velocidad frontal.

Por lo tanto, para extraer las variaciones de baja frecuencia de la temperatura del aire, se aplicó un filtro pasa bajo Butterworth de $4^{\circ}$ orden con una frecuencia de corte de 1/8 años a las mediciones de temperatura $T(t)$ detalladas en la sección 3.1. $T(t)$ contempla las variaciones de temperatura en un periodo comprendido entre 1996 y 2014. Los años que faltan para completar el periodo de 1994-2018, han sido extrapolados mediante una función de tendencia lineal (ver sección 5.1). Cabe destacar, que resulta relevante poder incluir en el modelo un periodo prolongado libre de formación de dique de hielo y sobre todo considerar los represamientos registrados en 2016 y 2018 , ya que estos últimos han sido los más importantes en cuanto a la robustez del dique y magnitud de niveles de agua alcanzados. Es por ello que se decidió extrapolar los datos de temperatura para completar el periodo 1994-2018.

Tomando la variación de velocidad de flujo de hielo de Sugiyama et al. (2011) y la temperatura del aire filtrada, podemos definir

$$
U_{m}(t)_{l t}=0.053 T(t)_{l t}+0.88,
$$


donde $U_{m}(t)_{l t}$ es la velocidad frontal de largo periodo en $\mathrm{m} / \mathrm{d}$ y $T(t)_{l t}$ es la variación de largo periodo de la temperatura del aire en $\mathrm{C}^{\circ}$. De esta forma, cuando el switch (a) de la Figura 3 esté habilitado, la amplitud de la velocidad frontal $U_{m}(t)$ (alta frecuencia) es variada (modulada) en proporción a $U_{m}(t)_{l t}$ (baja frecuencia).

\section{Resultados del Modelo}

\subsection{Pre-procesamiento}

Como se describió en la sección 3.1, algunas variables de entrada tienen etapas de pre-procesamiento de ajuste de curvas y filtrado para adecuar los datos antes de ingresar al sistema. En la gráfica (a) de la Tabla 2 se muestra la velocidad del flujo de hielo frontal diaria estimada a partir del método Fourier de ajuste de curvas (Fig. 3) tomando la media mensual de la variación anual de la velocidad frontal. Además, en la tabla se muestran la gráfica con los residuos del proceso de ajuste, la función $U_{m}(t)$ estimada para el periodo 1994-2018, el valor de los coeficientes, el $R$-square y RMSE (Root-Mean-Square-Error) calculados. Como indica la tabla, el proceso de ajuste pudo alcanzar un R-square $>$ 0,9 con un solo término sinusoidal, dado que la señal presenta una forma netamente estacional-sinusoidal.

Tabla 2. Velocidad del flujo de hielo frontal diaria estimada a partir del método Fourier de ajuste de curvas (línea azul) tomando la media mensual de la variación anual de la velocidad $U_{m}(t)$ rontal (línea color negra). Además, se aprecian los residuos del proceso de ajuste, la función estimada para el periodo 1994-2018, el valor de los coeficientes, el R-square y RMSE (Root-

Mean-Square-Error) calculados.

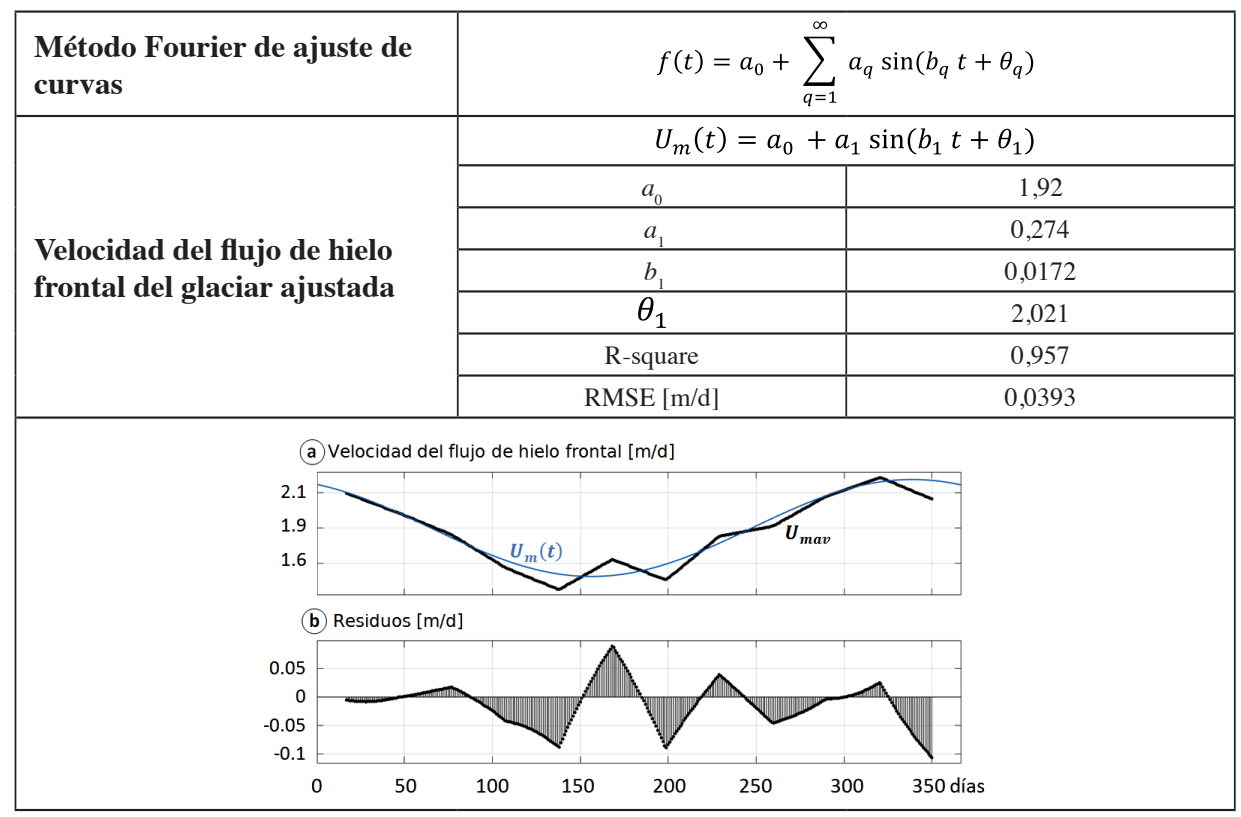


Del mismo modo, las gráficas de la Tabla 3 muestran los resultados para el caudal de entrada diario $\mathrm{Q}_{\mathrm{in} 1}(t)$ estimado a partir del método Fourier de ajuste de curvas. Como detalla la tabla, en este caso, el proceso de ajuste precisó de dos términos sinusoidales para alcanzar un R-square $>0,9$, dado que el caudal de entrada presenta una asimetría en los semi-periodos estacionales.

Tabla 3. Caudal de entrada diario estimado a partir del método Fourier de ajuste de curvas

(línea azul) tomando el caudal medio anual (línea color negra). Además, se aprecian los residuos del proceso de ajuste, la función $Q_{\text {inl }}(t)$ estimada para el periodo 1994-2018, el valor de los coeficientes, el R-square y RMSE (Root-Mean-Square-Error) calculados.

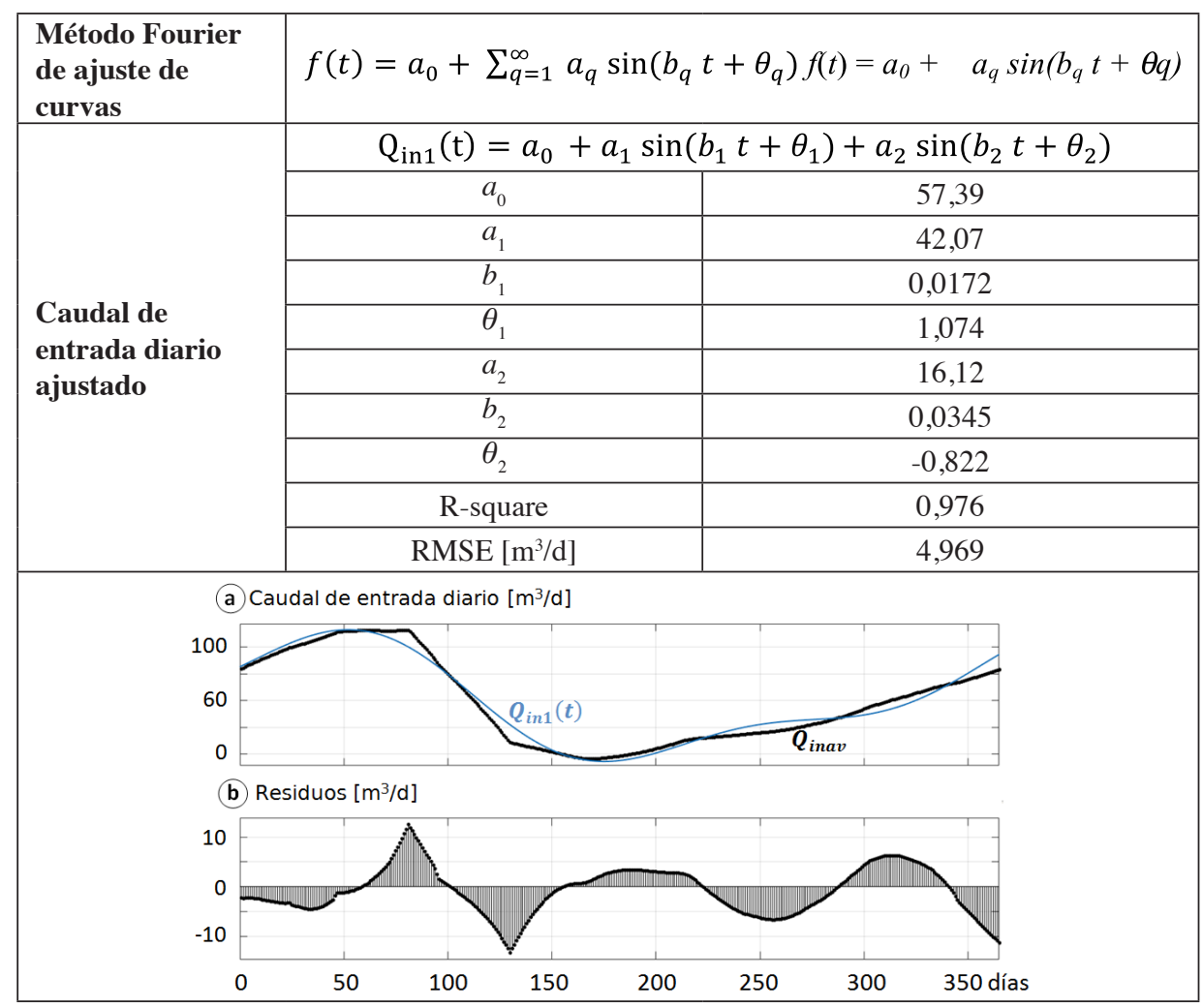

Por otro lado, en la Figura 4 se pueden observar las variaciones de largo periodo de la temperatura del aire $T(t)_{l t}$ obtenida a partir del filtrado de alta frecuencia de las mediciones de temperatura $(T(t))$. Esta variable es la que se utilizará en la ecuación (25) para modular $U_{m}(t)$. 


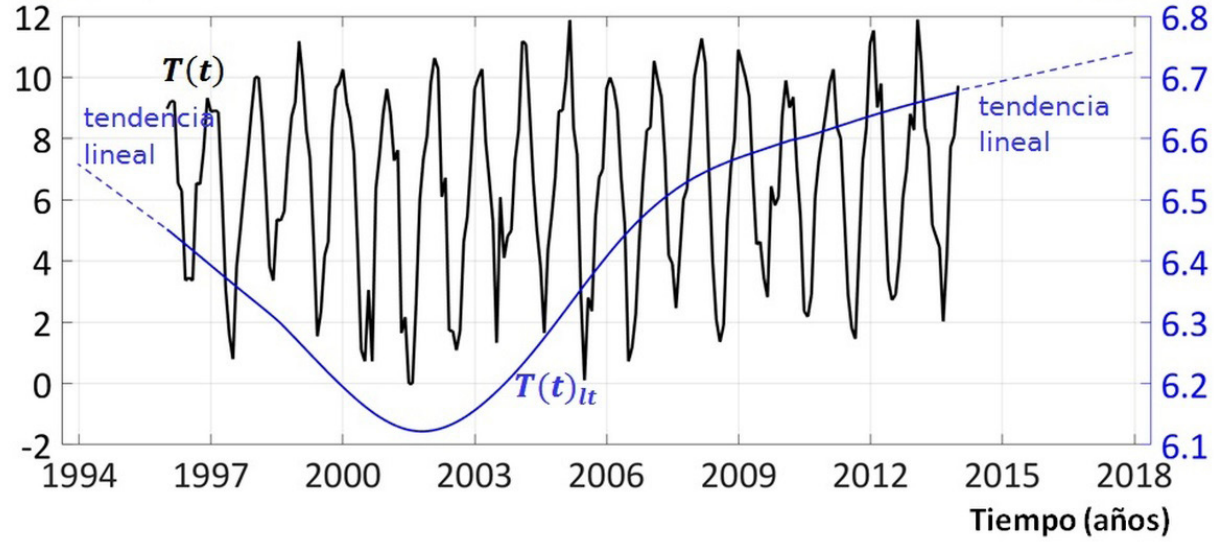

Figura 4. Mediciones de temperatura $(T(t))$ (línea negra) filtradas para obtener las variaciones de largo periodo de la temperatura del aire $T(t){ }_{l t}$ (línea azul continua). Además se muestran las funciones de tendencia lineal (línea color azul punteada) calculadas para

extrapolar los datos que faltan del periodo completo (1994-1996 y 2014-2018). Tanto

el eje derecho como el izquierdo de la gráfica, tienen unidades de temperatura, solo que presentan diferentes escalas para que se visualice mejor las variaciones relativas de largo periodo.

\subsection{Calibración del modelo}

\subsubsection{Modelo libre de variaciones de largo periodo}

Como se detalla en la sección 4, en primera instancia se realizó un proceso de calibración a partir de un modelo libre de variaciones de largo periodo (Fig. 3 switch (a) apagado). El primer proceso de calibración, basado en la búsqueda de la maximización de la función de correlación $r(j)$, demandó 1.454 .400 iteraciones totales, con 12.120 iteraciones $j$ para los parámetros de calibración $k_{2}, k_{3}$ y $k_{4}$ utilizando el método de búsqueda univariante secuencial y un promedio de 114,3 iteraciones para $k_{1}$ utilizando el método univariado Fibonacci de eliminación de intervalos. En la Tabla 1 se puede apreciar que la cantidad de iteraciones totales se redujo al 1,33\%. Esta considerable reducción se debe a la eficiencia del método Fibonacci que en promedio redujo al 1,27 \% las iteraciones para la búsqueda de $k_{1}$ óptimos. La Figura 5 muestra los valores de correlación $r(j)$ para las 12.120 iteraciones. Cada $j$ corresponde a un $k_{1}$ óptimo por cada iteración asignada por el método de búsqueda univariante secuencial para los tres restantes parámetros tomando los umbrales y pasos correspondientes (Tabla 1). Por lo tanto, cada pico de $r(j)$ de la figura, está compuesto por 101 iteraciones correspondiente a la variación de $k_{2}$ entre 1 y 2 con pasos de 0,01 dejando los correspondientes $k_{3}$ y $k_{4}$ constantes. Los máximos valores de correlación hallados pertenecen a los picos ubicados entre las iteraciones 2930 hasta la 3232 para un $k_{4}=0,3$ y un $k_{3}=[0,3 ; 0,4 ; 0,5]$. El $r(j)$ máximo es de 0,79 para un $\left\{k_{1}\right.$; 
$\left.k_{2} ; k_{3} ; k_{4}\right\}_{j}=\{0,0004746 ; 1,21 ; 0,5 ; 0,3\}_{3053}$, por lo que ningún valor superó el 0,98 , valor que simula la totalidad de los 8 eventos de formación de diques de hielo.

Evaluando la función $r(j)$ se puede apreciar que cada pico correspondiente a cada variación de $k_{2}$, presenta el mismo comportamiento. Todos los picos comienzan con valores de correlaciones bajas (Fig. 5a-b), donde el modelo presenta una serie de eventos caracterizados por la simulación de un represamiento siempre antes del 2004 (Fig. 6ab). Como muestra la ecuación (13), esto se debe a que los valores de $k_{2}$ bajos producen que $a_{d w}$ sea bajo y entonces, el glaciar no encuentra resistencia y alcanza la PM antes de lo estipulado. Una vez que el valor de $k_{2}$ aumenta hasta que la simulación produce el primer dique de hielo en el 2004 (Fig. 5c y Fig. 6c), los valores de $r(j)$ se mantienen altos y simulan una serie de represamientos posteriores sin poder representar los 8 eventos totales en ningún caso. Esto sucede dado que a medida que $k_{2}$ sigue aumentando, $a_{d w}$ tiende a mantener alejado el frente del glaciar de la PM (Fig. 5d-e y Fig. 6d-e) hasta llegar hacer $r(j)=0$ donde siempre $D_{p g}(t)$ es mayor a cero (Fig. 5f y Fig. 6f). En definitiva, para que la simulación incluya los eventos faltantes $n=2,4,6(2006,2012,2013 \mathrm{~b})$ para

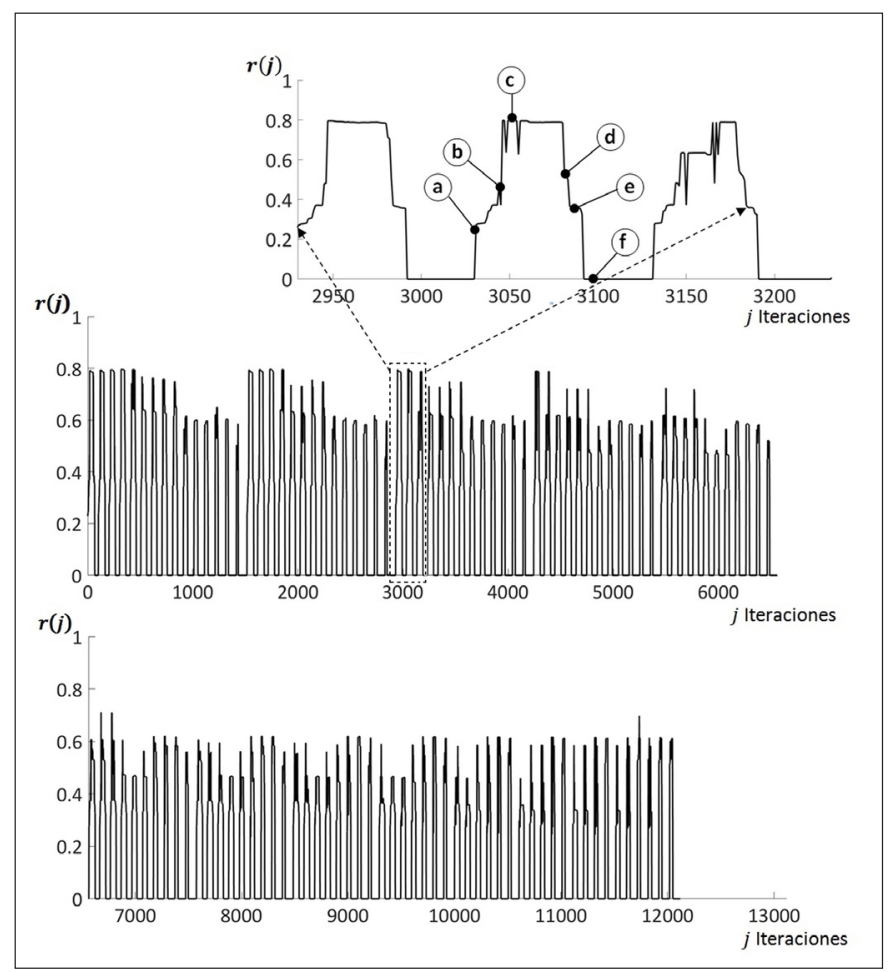

Figura 5. Valores de correlación r(j) para las 12.120 iteraciones divididas en dos graficas $11 \leq$ $j \leq 6560 ; 6561 \leq j \leq 12.120$ ] para una mejor visualización. La ampliación en la figura superior denota los máximos valores de correlación que corresponden a los picos ubicados entre las iteraciones 2930 hasta la 3232. Los puntos indicados con $(a),(b),(c),(d),(e)$ y $(f)$ describen un ejemplo del cambio de comportamiento general de los picos con los valores de correlación para el conjunto de iteraciones de los $r(j)$. 


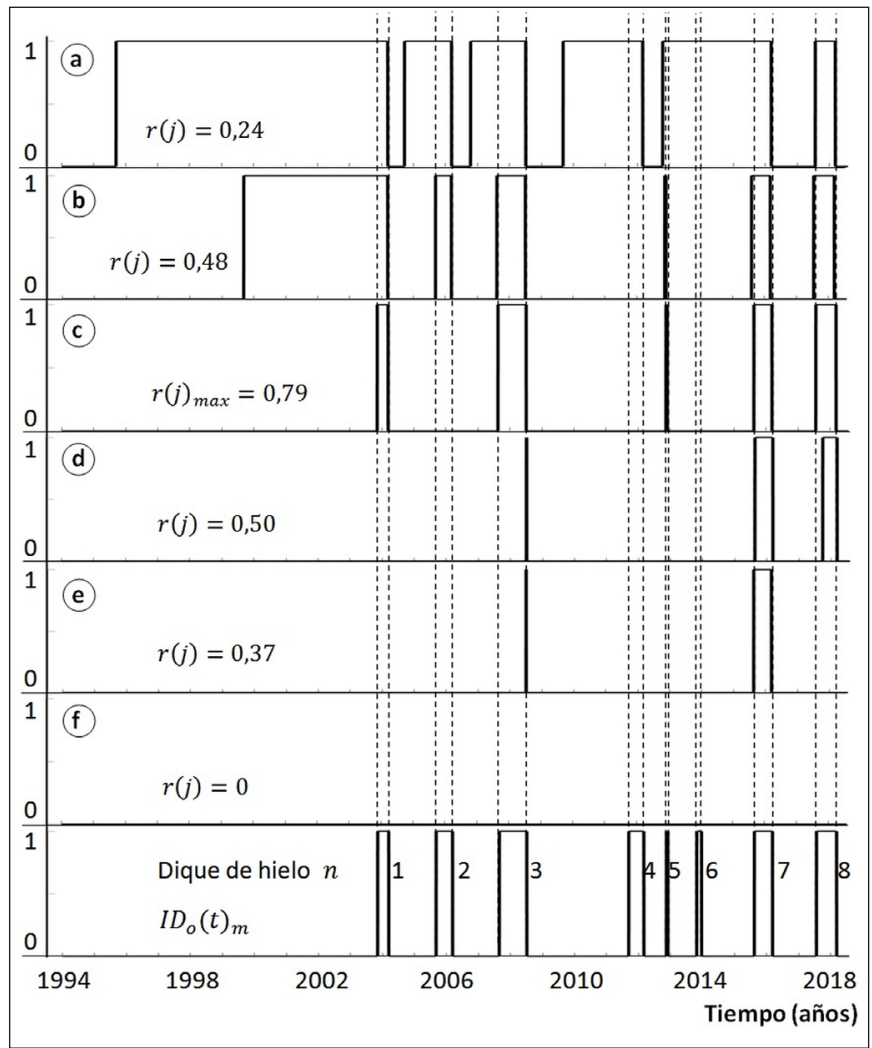

Figura 6. Ejemplo del comportamiento general de las funciones de correlación simuladas para las iteraciones comprendidas entre los $j=3.031$ hasta $j=3.131$. Nótese que los casos $(a),(b)$, $(c),(d),(e)$ y $(f)$ corresponden a los puntos mostrados en la Figura 5. En la parte inferior se muestra la ocurrencia de formación de diques de hielo medidas $I D_{o}(t)_{m}$, donde se detallan los 8 represamientos producidos entre los años 1994-2018.

$r(3053)=0,79$, debe bajar el valor de $k_{2}$, sin embargo, ante esta condición el modelo simula un evento antes del 2004. Dado este comportamiento de la función de correlación, el modelo no puede simular la totalidad de los eventos, por lo tanto, no puede aplicarse el segundo proceso de calibración que conlleva a que MO-ACAR no pueda ser validado, independiente de la metodología y configuración de la calibración utilizada.

\subsubsection{Modelo con variación de largo periodo de temperatura del aire}

A partir del primer proceso de calibración, pero esta vez teniendo en cuenta la variación de la velocidad del flujo del glaciar de largo periodo (Fig. 3 switch (a) encendido), se obtuvo $r(j)$ para las 12.120 iteraciones.

Como muestra la Figura 7, existen tres grupos con valores de correlación altos. El primer y segundo grupo están comprendidos en los picos [4445 $\leq j \leq 4545$ ] y [5556 $\leq j \leq 5656$ ] respectivamente, marcados como (a) en la gráfica, mientras que el tercer 


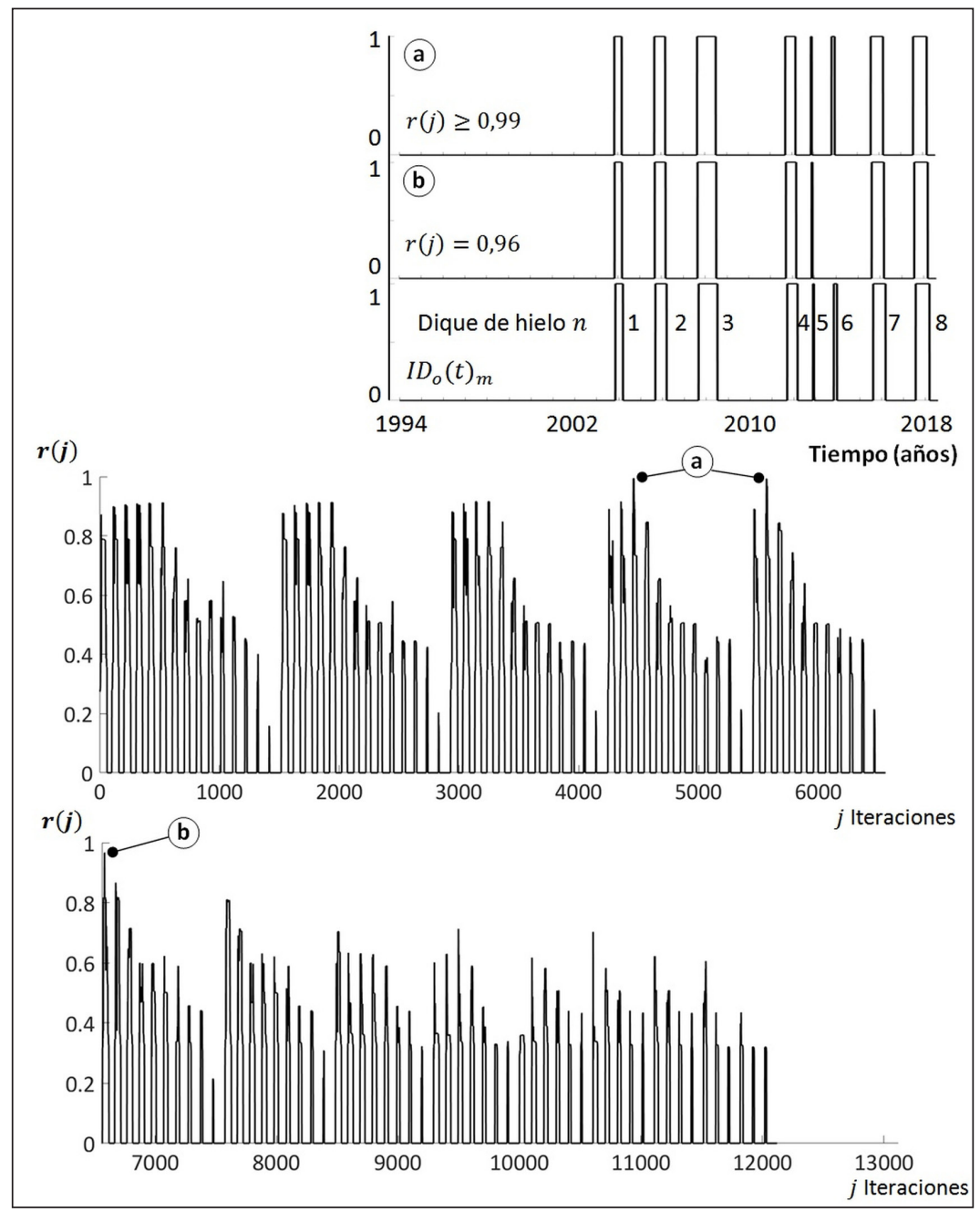

Figura 7. Valores de correlación $r(j)$ para las 12.120 iteraciones divididas en dos graficas $[1 \leq$ $j \leq 6560 ; 6561 \leq j \leq 12.120$ ] para una mejor visualización, teniendo en cuenta las variaciones de largo periodo de temperatura del aire. La imagen en la parte superior, indica los mayores valores de correlación hallados de manera ampliada, donde se destaca el pico (b), el cual no supero el valor de 0,98 y además, los picos (a) que si lo superaron, a partir de los cuales se calibró el modelo.

grupo corresponde al pico [6566 $\leq j \leq 6666]$ marcado como (b). Solo los valores de los primeros dos picos han superado el 0,98 , por lo tanto, solo los parámetros de calibración comprendidos en estos máximos simulan la totalidad de los eventos. Un total de 9 candidatos $c v_{o}(p)=\left\{k_{1} ; k_{2} ; k_{3} ; k_{4}\right\}$ fue hallado en estos grupos, mediante este proceso de optimización (Tabla 4 ). 
Tabla 4 . Valores de los parámetros $\left(k_{1}, k_{2}, k_{3}, k_{4}\right)$ encontrados en el segundo proceso de calibración, teniendo en cuenta la variación de largo periodo de la temperatura del aire para los 9 candidatos $c v$. Se observa la alta correlación hallada durante el proceso $(0,99)$, y los errores medios y STD de la posición frontal del GPM. Además, se remarca el candidato óptimo cv ${ }_{o}(6)$, el cual presenta el error $e_{W L S}(p)$.

\begin{tabular}{|c|c|c|c|c|c|c|c|}
\hline \multicolumn{7}{|c|}{ Parámetros } & \multicolumn{2}{|c|}{$\boldsymbol{e}_{W L S}(\mathbf{p})$} \\
\hline $\boldsymbol{c} \boldsymbol{v}_{\boldsymbol{o}}(\mathbf{p})$ & $\boldsymbol{r}(\mathbf{j})$ & $\boldsymbol{k}_{\mathbf{1}}$ & $\boldsymbol{k}_{\mathbf{2}}$ & $\boldsymbol{k}_{\mathbf{3}}$ & $\boldsymbol{k}_{\mathbf{4}}$ & Media [m] & STD [m] \\
\hline $\boldsymbol{c} \boldsymbol{v}_{\boldsymbol{o}}(\mathbf{1})$ & 0,9942 & 0,0006678 & 1,10 & 0,6 & 0,4 & 15,02 & $\pm 21,83$ \\
\hline $\boldsymbol{c} \boldsymbol{v}_{\boldsymbol{o}}(\mathbf{2})$ & 0,9942 & 0,0006253 & 1,11 & 0,6 & 0,4 & 13,76 & $\pm 20,03$ \\
\hline $\boldsymbol{c} \boldsymbol{v}_{\boldsymbol{o}}(\mathbf{3})$ & 0,9942 & 0,0005828 & 1,12 & 0,6 & 0,4 & 13,13 & $\pm 19,11$ \\
\hline $\boldsymbol{c} \boldsymbol{v}_{\boldsymbol{o}}(\mathbf{4})$ & 0,9946 & 0,0005442 & 1,13 & 0,6 & 0,4 & 12,22 & $\pm 17,79$ \\
\hline $\boldsymbol{c} \boldsymbol{v}_{\boldsymbol{o}}(\mathbf{5})$ & 0,9946 & 0,0005094 & 1,14 & 0,6 & 0,4 & 11,12 & $\pm 16,21$ \\
\hline $\boldsymbol{c} \boldsymbol{v}_{\boldsymbol{o}}(\mathbf{6})$ & 0,9937 & 0,0004785 & 1,15 & 0,6 & 0,4 & 9,56 & $\pm 13,94$ \\
\hline $\boldsymbol{c} \boldsymbol{v}_{\boldsymbol{o}}(\mathbf{7})$ & 0,9933 & 0,0007103 & 1,10 & 0,6 & 0,5 & 15,30 & $\pm 22,09$ \\
\hline $\boldsymbol{c} \boldsymbol{v}_{\boldsymbol{o}}(\mathbf{8})$ & 0,9933 & 0,0006640 & 1,11 & 0,6 & 0,5 & 14,71 & $\pm 21,23$ \\
\hline $\boldsymbol{c} \boldsymbol{v}_{\boldsymbol{o}}(\mathbf{9})$ & 0,9933 & 0,0006176 & 1,12 & 0,6 & 0,5 & 13,66 & $\pm 19,69$ \\
\hline
\end{tabular}

Para el segundo proceso de calibración, se corrió el programa tomando estos 9 candidatos $c v_{o}(p)$ y se calculó el $e_{W L S}(p)$ entre $D_{p g}(t)_{m}$ y $D_{p g}(t)$. Los resultados del error están listados en la tabla 4 , donde se muestran el error medio y la desviación estándar (STD), y en la que se aprecia que los parámetros de calibración óptimos $\left\{k_{1} ; k_{2} ; k_{3} ; k_{4}\right\}_{\text {op }}$ que simulan la distancia del glaciar a la península con menor error, corresponden al candidato $6(p=6)$. El error obtenido $e_{W L S}(6)=9,56 \pm 13,94 \mathrm{~m}$ resulta satisfactorio considerando que representa menos del $10 \%$ de las oscilaciones promedio que experimenta el GPM $(122,1 \mathrm{~m})$. De esta manera el MO-ACAR ha sido calibrado y validado, y a partir de este modelo se realizarán las simulaciones del comportamiento del GPM.

\subsection{Simulación de la posición frontal y ocurrencia de formación de diques de hielo}

A continuación se presenta el comportamiento del GPM de acuerdo a los resultados de la simulación del modelo MO-ACAR validado, tomando los parámetros de calibración $c v_{o}(6)$. La distancia del frente del glaciar $D_{p g}(t)$ (Fig. 8a) y la variable de ocurrencia de formación de diques de hielo $I D_{o}(t)$ (Fig. 8b) simuladas muestran un periodo libre de represamientos (1994-2003), y luego, un periodo donde el glaciar alcanza la PM formando diques de hielo completos de manera recurrente y aperiódica (2004-2018). Como muestra la simulación, al comienzo el frente del glaciar se halla a $250 \mathrm{~m}$ de la península, por lo tanto, el área de descarga efectiva resulta grande por lo 
que la velocidad del agua que circula por el canal es mínima y la posición del frente del glaciar queda gobernada prácticamente solo por la resultante entre $U_{m}$ y $\dot{a}$. Es por ello, que en este punto la simulación muestra un avance y aproximación del frente del glaciar a la PM. Según el modelo, a partir de una distancia promedio de $112 \mathrm{~m}$ (dependiendo del valor de $\mathrm{Q}_{\mathrm{in1}}(\mathrm{t})$ ), el frente del glaciar comienza a producir un desnivel h(t) (Fig. 8a) por lo que la velocidad del agua de descarga comienza a incidir en la ablación total que experimenta el glaciar. Desde el inicio de la simulación hasta octubre del 2003, los resultados exponen que el GPM experimenta oscilaciones sostenidas con frecuencia anual y amplitud pico a pico promedio de 101,4 m. En este periodo de más de 8 años el frente se aproxima a una distancia en su pico mínimo promedio de 15,7 m. Sin embargo, para ningún año la variable alcanza la PM, por lo tanto, el área efectiva nunca se hace cero y no se da inicio a un proceso de represamiento. Durante este periodo, el h(t) también presenta oscilaciones sostenidas, donde se destaca que nunca se hace cero. Esto indica que, si bien el GPM no alcanza la PM, existe una $a_{d w}$ que debe estar participando en la oscilación del frente.

Si comparamos los resultados obtenidos para un modelo libre de variaciones de largo periodo, el cual no pudo ser validado, frente al de variaciones de largo periodo de temperatura del aire, podríamos relacionar este periodo sin represamientos con el periodo de tendencia a la baja de temperatura, seguido de un periodo de calentamiento, caracterizado por una secuencia continuada de eventos (Fig. 4). La tendencia de enfriamiento de la temperatura del aire mostrado en la Figura 4 (1994-2002), modula $U_{m}$ según la ecuación (25), de manera que la disminución de la velocidad tiende a alejar el GPM de la PM. A partir del 2002, la tendencia en ascenso de la temperatura aumenta la $U_{m}$ y el glaciar comienza a llevar su oscilación más cerca de la PM hasta que en un momento inicia un periodo caracterizado por sucesivos represamientos. En este periodo, según el modelo, cada represamiento presenta diferentes comportamientos que dependen tanto de las características propias del evento, como así también, de las condiciones del evento previo. Por ejemplo, siguiendo con la secuencia temporal, en octubre del 2003 el glaciar alcanza la PM y da comienzo al primer dique de hielo ( $n$ $=1$ ). La altura del nivel de agua comienza a elevarse hasta alcanzar su máximo para un $t_{d d}=11$ de marzo del 2004. En este momento, la ruptura del dique hace que el agua comience a circular por el canal y a liberar la energía potencial acumulada. La tasa de ablación se incrementa de manera abrupta, al acelerarse súbitamente la velocidad del agua en el canal, haciendo que el frente del glaciar retroceda en 10 días hasta $186 \mathrm{~m}$ de la península. Como indica la Figura 8, durante este periodo se destaca que el nivel de agua tiende a nivelarse $(\mathrm{h}(\mathrm{t}) \rightarrow 0)$, debido al fuerte retroceso del glaciar, donde $D_{p g}(t)$ supera los $112 \mathrm{~m}$ haciendo que el área efectiva sea lo suficientemente grande para igualar los niveles entre el BR y el CT. En esta instancia, cabe destacar que la fase de aproximación del glaciar a la PM depende netamente de los valores estacionales de $U_{m}$ y $\dot{a}$, que en definitiva controlan el subsiguiente evento de represamiento. En este evento (2004), la retracción retira fuertemente al GPM, por lo tanto, en el año siguiente el glaciar avanza hasta una distancia mínima de 21,4 m para octubre del 2004, sin poder alcanzar la PM. Luego, al siguiente año el GPM vuelve a represar en agosto del 2005. Como muestra la Figura 8, la acumulación del nivel de agua describe 
un comportamiento particular, en relación con otros represamientos, donde h(t) deja de incrementarse a partir del 17 de enero del 2006 hasta el 10 de marzo del 2006 cuando se produce la descarga, limitando el máximo de energía potencial alcanzada. Este proceso puede estar relacionado con la robustez del dique (capacidad de retener el agua libre de infiltraciones) (Lenzano et al., 2018). De este modo, a partir del 17 de enero el dique de hielo podría haber tenido filtraciones paulatinas antes del inicio de descarga abrupta. Debido a ello, el modelo muestra que el represamiento de 2006 produjo una retracción menor que el anterior $\left(D_{p g}(t)=149,7 \mathrm{~m}\right)$, que hace que para la siguiente oscilación el GPM esté muy cerca de alcanzar la PM $\left(D_{p g}(t)=6,3 \mathrm{~m}\right)$, sin embargo, no se produce un represamiento. Para eventos donde la retracción es menor aún, debido a la baja acumulación de energía potencial, la simulación demuestra que $D_{p g}(t)$ puede hacerse cero al siguiente año, generando así diques de hielo anuales como el caso de los eventos $n=4,5,6$ (2012, 2013a, 2013b).

Otro ejemplo particular corresponde al evento 2008, el cual está caracterizado por un inicio temprano (agosto 2007) y una descarga tardía (julio 2008) relacionada por las características del evento previo y la robustez del dique alcanzada para ese año. En este caso, la descarga tardía produce una fase de retroceso diferente a los demás eventos, donde el efecto de $a_{d w}{ }_{d w}$ se ve disminuido porque en julio la resultante entre $U_{m}$ y $\dot{a}$ es favorable al avance del glaciar. Esto hace que, para el siguiente año, la simulación muestre el frente del glaciar alejado de la PM con un pico mínimo para diciembre del 2008 de 57 m. Este fenómeno causó que el próximo represamiento comience para octubre del 2011.

El evento 2016 presenta un comportamiento similar a los eventos 2004 y 2006, los cuales producen eventos cada 2 años. El represamiento de 2018 es el evento que mayor energía potencial ha acumulado durante el periodo de estudio, el cual superó los 11 m de diferencia entre $C T L(t)$ y $B R L(t)$. En síntesis, realizando un análisis general de los eventos simulados, podemos definir que una vez que el glaciar entra en la etapa donde la velocidad del flujo del hielo es modulada por el calentamiento, la ocurrencia y características de cada dique de hielo dependen fundamentalmente de la fase y robustez del evento previo, y de la robustez del evento actual. Por último, cabe destacar la similitud entre la posición frontal simulada por el modelo y los valores de posición frontal medidos a través de imágenes satelitales y del procesamiento fotogramétrico time-lapse (Fig. 8a). 


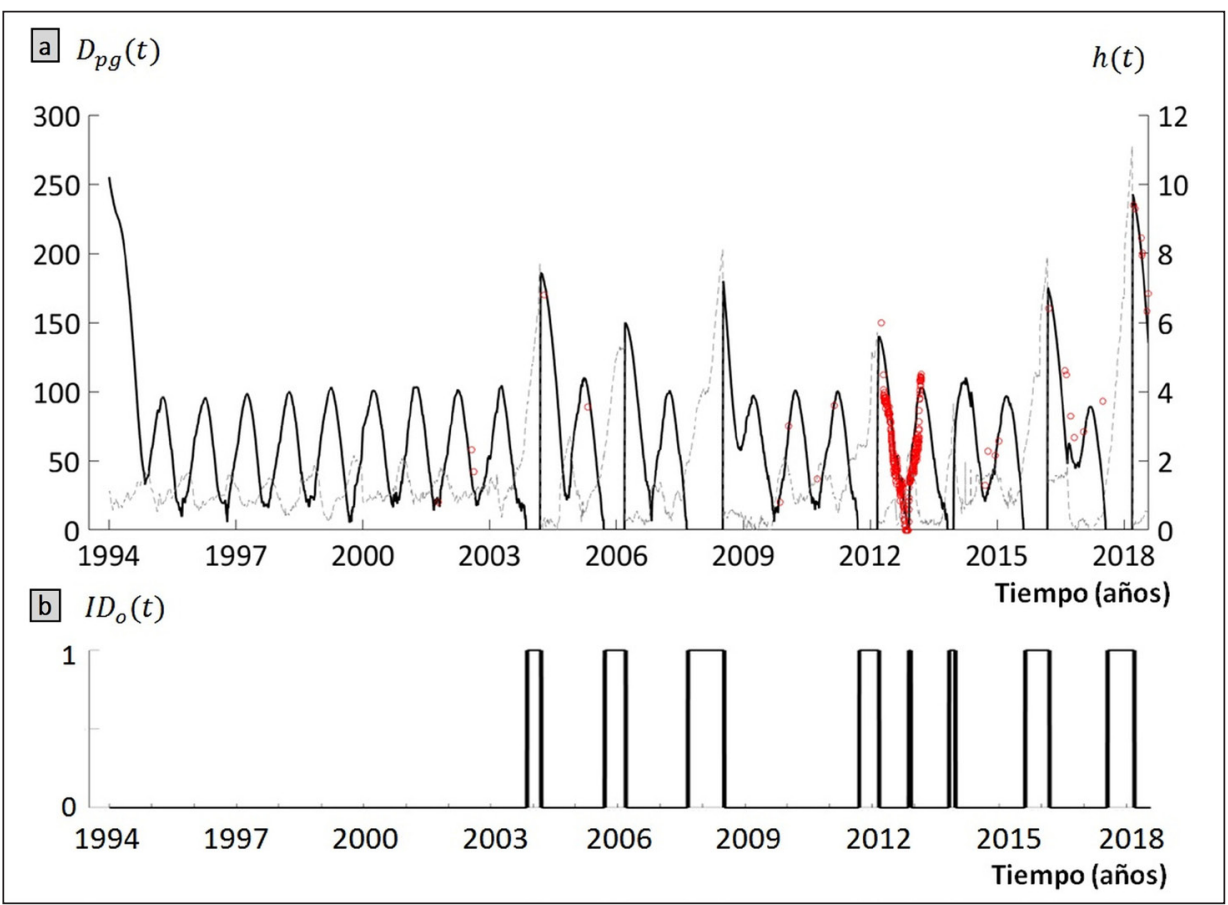

Figura 8. Simulaciones del modelo MO-ACAR validado para el periodo 1994-2018. La línea de color negro simula la oscilación de la distancia del frente del glaciar $D_{p g}(t), y$ además, se muestra la diferencia de alturas del nivel de agua diarias $h(t)$ en línea punteada de color gris. En círculos rojos se marcan los valores de posición frontal medidos a través de imágenes satelitales $y$ del procesamiento fotogramétrico time-lapse. Además, en la parte inferior de la figura, se muestra la variable de ocurrencia de formación de diques de hielo simulada.

\section{Discusión}

Los resultados de la simulación del modelo validado establecen que el comportamiento del GPM está gobernado por procesos con diferentes escalas temporales. La dinámica oscilatoria del glaciar y la ocurrencia de formación de diques de hielo, están controlados por procesos con cortos e intermedios periodos temporales. En estos dos períodos intervienen variables con componentes de frecuencias diarias y estacionales, como así también la concatenación de los procesos de represamiento. Por ejemplo, en escalas temporales de días, meses o estacionales, la dinámica del glaciar es controlada por procesos como la ablación, derretimiento, velocidad basal, etc. La concatenación de los procesos influye en la ocurrencia y características de cada dique de hielo, dado que, por ejemplo, la fase y robustez del evento previo tiene incidencia sobre el evento subsiguiente. A su vez, la modulación de baja frecuencia de la velocidad del flujo de hielo provocada por las variaciones de largo periodo de la temperatura del aire incide en la formación de periodos con diques de hielo y libres 
de éstos. Ambos aspectos conllevan a enfocar el análisis de la dinámica del GPM a diferentes escalas temporales.

Como muestra el trabajo de Guerrido et al. (2014), el frente del GPM en los años 1700-1800 estuvo más alejado de la PM que lo que está actualmente. Hauthal (1904) describe que en 1899 el frente se encontraba a 1 km de la PM, luego la posición frontal avanzó hasta alcanzarla en 1917, período a partir del cual el glaciar comenzó a mostrar un patrón oscilatorio próximo a la península (Skvarca y Naruse, 1997). Según los resultados del presente estudio, este particular comportamiento puede estar relacionado con la variación de periodo largo de la temperatura. La reconstrucción de la temperatura media anual para el área del CHPS realizada por Villalba et al. (2003), muestra que a partir de mediados del 1600 existe una tendencia de aumento de la temperatura media anual. Desde el año 1900, las anomalías de las temperaturas tienden a ser superiores a la media reconstruida. Por lo tanto, años antes de principios del siglo XX, el glaciar se ubicaba alejado de la PM, en un sector con mayor profundidad del lago proglacial y dentro de un periodo más frío. Bajo estas condiciones, el calving, controlado principalmente por la profundidad del lago, pudo mantener al glaciar apartado de la península y libre de formación de diques de hielo, como sugiere Guerrido et al. (2014). Luego, la tendencia sostenida de calentamiento y el consiguiente aumento de la velocidad basal del flujo de hielo, pudo haber llevado a que el GPM se aproxime a la PM provocando los recurrentes represamientos dentro del periodo donde la temperatura tiende a superar la media reconstruida (1900-actualidad). En este punto, comienza la interacción de la parte terminal del glaciar con la península, dando lugar al proceso oscilatorio analizado y simulado en el presente trabajo.

Haciendo un análisis más general, cabe destacar que el cambio de velocidad basal puede tener distintas implicaciones en la dinámica de un glaciar. Si se hace un supuesto sobre si el glaciar avanza una determinada distancia aguas abajo por el valle, debido al aumento de la velocidad basal en el comienzo de un periodo de calentamiento, se podrían suceder dos situaciones hipotéticas a saber:

(i) en el caso de la Figura 9a, un avance del frente conduce al glaciar a una zona más baja donde los procesos de ablación aumentan, favoreciendo así a la pérdida de masa de hielo debido a los procesos de derretimiento, sublimación, evaporación, etc. A su vez, la tasa de calving aumenta debido a procesos de flotación y al incremento de esfuerzos mecánicos longitudinales asociados con los gradientes de velocidad, intensificándose aún más si el glaciar avanza hacia zonas con mayor profundidad del lago proglacial (Benn y Evans, 2014). De esta forma, este proceso de realimentación negativa, provocará que la posición neta del frente del glaciar sea de retracción.

(ii), en el caso que muestra la Figura 9b, si el avance de la parte terminal del glaciar conduce a una topografía con una reducción de la profundidad del lago (por ejemplo, una península), se produce un proceso con realimentación positiva. En principio, al descender el frente del glaciar por el valle aumenta la ablación, sin embargo, si el avance es bajo en términos de procesos de ablación, comparado con los cambios de la topografía, el glaciar podría entrar en una zona favorable para el avance. En este tipo de glaciares, el calving puede estar gobernado principalmente por procesos de flotación 
vinculados con la relación entre la altura del glaciar y la profundidad del lago (Benn y Evans, 2014). En este sentido, como indica el caso (ii), el glaciar fluye hacia una zona donde los procesos de flotación disminuyen al perder profundad el lago, que conlleva a un avance neto del frente que conduce nuevamente a zonas menos profundas. Este condicionamiento topográfico es poco usual y por ello la gran mayoría de los glaciares del CHPS no presentan este proceso de realimentación positiva. Ejemplos de este caso particular, corresponden a los glaciares Pio XI (o Glaciar Brüggen) y el GPM, los cuales se encuentran estables o incluso en avance como el Pio XI (Rivera, 1992; Rivera et al., 1997; Warren et al., 1997; Rivera y Casassa, 1999). En el caso del GPM, si el glaciar avanza mediante esta realimentación positiva y vence la retracción producida por el agua de descarga del canal formado, el frente alcanzará el final de la topografía anulando en definitiva el caudal de descarga. Si en la división total del lago (BR-CT) los dos reservorios de agua tuviesen caudales de descarga que limiten los niveles máximos de los lagos a valores bajos, es posible que con el tiempo el glaciar avanzaría bifurcándose y cubriendo parte del CT y BR hasta encontrar un nuevo equilibrio aguas abajo de donde está localizado en la actualidad. No obstante, debido a que uno de los reservorios (BR) tiene niveles de salida restringidos, (30,8 m, Sersic, 1988) el glaciar es modulado por el proceso de acumulación sostenida de volumen de agua y posterior descarga por el canal que puede ser continua (cuando no hay dique hielo) o discontinua/abrupta (cuando existe dique hielo) que hace que en definitiva el frente del glaciar oscile.
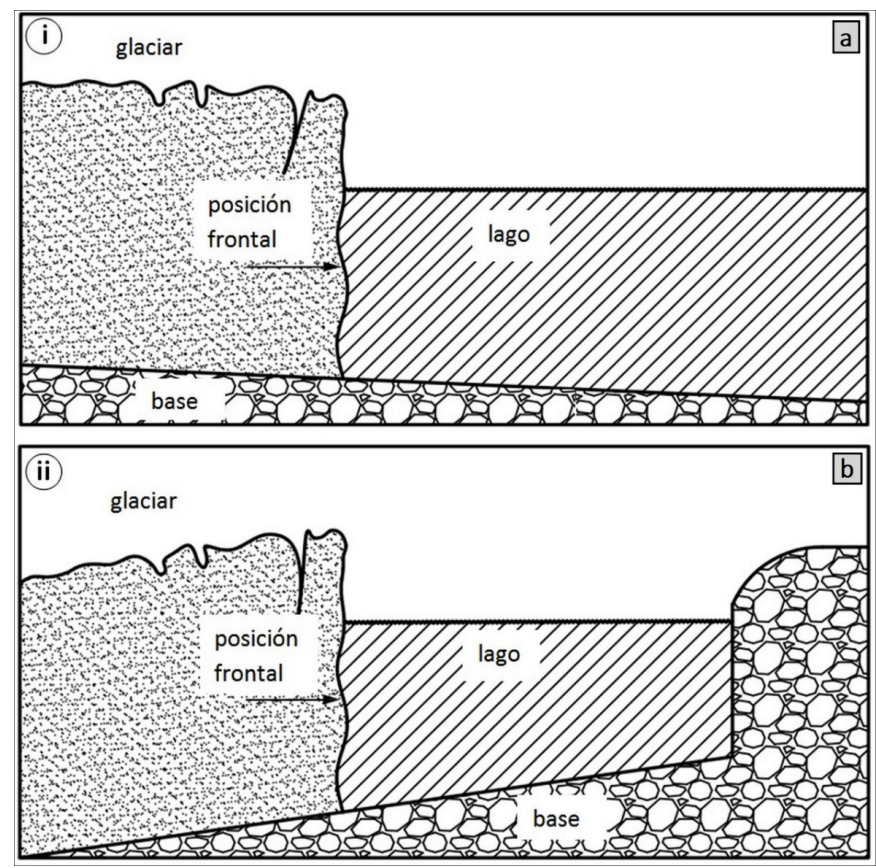

Figura 9. Patrones topográficos condicionantes en el retroceso y el avance de los glaciares de calving. a) realimentación negativa: el glaciar presenta retracción neta. b) realimentación positiva: el glaciar presenta avance neto. 


\section{Conclusiones}

En el presente estudio se ha desarrollado un modelo numérico computacional para estudiar las oscilaciones de la posición frontal y la ocurrencia en la formación de diques de hielo en el Glaciar Perito Moreno, un glaciar de agua dulce localizado en el Campo de Hielo de la Patagonia Sur, desde 1994 hasta 2018. El modelo denominado MOACAR, ha sido calibrado y validado a partir de un proceso de optimización iterativo, basado en la maximización de valores de correlación y minimización de errores de distancia entre las simulaciones y mediciones de la ocurrencia de represamientos y la posición del frente de hielo, respectivamente. El modelado ha logrado alcanzar altas prestaciones y demuestra la sensibilidad del modelo numérico teórico para emular la dinámica real del GPM, con una correlación para la ocurrencia de 0,99 y errores en la posición frontal de 9,56 $\pm 13,94 \mathrm{~m}$. Los resultados arrojados por el modelo han demostrado que el concepto Avance-Cierre-Apertura-Retroceso (ACAR) explica con precisión el comportamiento oscilatorio estacional que presenta la posición frontal del glaciar. Además, las simulaciones ayudaron a entender los procesos que controlan la ocurrencia de la formación de diques de hielo, como así también a los periodos libres de represamientos.

En síntesis, se puede argumentar que la dinámica del glaciar y la formación de diques de hielo responden a procesos que actúan a diferentes escalas temporales. En cortos e intermedios periodos temporales, la ocurrencia depende tanto de las características propias del evento, como de la fase y robustez del evento previo. En largos periodos temporales, la modulación de baja frecuencia de la velocidad del flujo de hielo provocada por las variaciones de la temperatura del aire incide en la formación de periodos con diques de hielo y libres de éstos. Se propone como trabajo futuro extender el estudio de la dinámica del GPM asociado a una reconstrucción climática de mayor periodo, que la actualmente estudiada, con el objetivo de extender este estudio a todos los represamientos registrados $(1917,1935,1940,1942,1947,1952,1953,1956$, 1960, 1963, 1966, 1970, 1972, 1975, 1977, 1980, 1984, 1988, 2004, 2006, 2008, 2012, 2013a, 2013b, 2016 y 2018).

\section{Agradecimientos}

La investigación fue financiada por la Agencia Nacional de Ciencia y Tecnología de Argentina y Consejo Nacional de Investigaciones Científicas y Técnicas (CONICET, Argentina). Los autores desean agradecer a Administración de Parques Nacionales (APN) y Parque Nacional Los Glaciares de la Provincia de Santa Cruz, Argentina, a Adalberto Ferlito, Paulina Vacaflor y Ricardo Villalba por su colaboración durante las campañas de campo y la preparación del manuscrito.

\section{Referencias}

Aniya, M., Skvarca, P. 1992. Characteristics and variations of Upsala and Moreno glaciers, southern Patagonia. Bulletin Glacier Research 10, 39-53. http://www.seppyo.org/bgr/pdf/10/ BGR10P39.PDF. 
Aniya, M., Sato, H., Naruse, R., Skvarca, P., Casassa, G. 1996. The use of Satellite and Airborne Imagery to Inventory Outlet Glaciers of the Southern Patagonia Icefield, South America. Photogrammetric Engineering \& Remote Sensing 62 (12), 1361-1369. http://worldcat.org/ issn/00991112.

Abuelma'atti, M.T. 1993. A simple algorithm for fitting measured data to Fourier-series models. Integrated Education 24 (1), 107-112. https://doi.org/10.1080/0020739930240114.

Benn, D., Evans, D.J. 2014. Glaciers and glaciation. Routledge. https://doi. org/10.4324/9780203785010.

Ciappa, A., Pietranera, L., Battazza, F. 2010. Perito Moreno Glacier (Argentina) flow estimation by COSMO SkyMed sequence of high-resolution SAR-X imagery. Remote Sensing of Environment 114 (9), 2088-2096. https://doi.org/10.1016/j.rse.2010.04.014.

Cuffey, K.M., Paterson, W.S.B. 2010. The physics of glaciers. Academic Press.

Dahabreh, I.J., Chan, J.A., Earley, A., Moorthy, D., Avendano, E.E., Trikalinos, T.A., Balk, E.M., Wong, J.B. 2017. Modeling and Simulation in the Context of Health Technology Assessment: Review of Existing Guidance, Future Research Needs, and Validity Assessment. https:// www.ncbi.nlm.nih.gov/pubmed/28182366.

Ferguson, D.E. 1960. Fibonaccian searching. Communications of the ACM 3 (12), 648. https:// doi.org/10.1145/367487.367496.

Foresta, L., Gourmelen, N., Weissgerber, F., Nienow, P., Williams, J.J., Shepherd, A., Drinkwater, M.R., Plummer, S. 2018. Heterogeneous and rapid ice loss over the Patagonian Ice Fields revealed by CryoSat-2 swath radar altimetry. Remote Sensing of Environment 211, 441-455. https://doi.org/10.1016/j.rse.2018.03.041.

Guerrido, C.M., Villalba, R., Rojas, F. 2014. Documentary and tree-ring evidence for a long-term interval without ice impoundments from Glaciar Perito Moreno, Patagonia, Argentina. The Holocene 24 (12), 1686-1693. https://doi.org/10.1177/0959683614551215.

Hauthal, R. 1904. Gletscherbilder aus der argentinischen Cordillere. Zeitschrift des Deutschen und Österreichischen Alpenvereins 35, 30-56.

Jaber, A. 2016. Derivation of mass balance and surface velocity of glaciers by means of high resolution synthetic aperture radar: application to the Patagonian Icefields and Antarctica (Doctoral dissertation, Technische Universität München).

Jansson, P., Hock, R., Schneider, T. 2003. The concept of glacier storage: a review. Journal of Hydrology 282 (1-4), 116-129. https://doi.org/10.1016/S0022-1694(03)00258-0.

Lenzano, M.G., Lannutti, E., Toth, C., Lenzano, L., Lo Vecchio, A., Falaschi, D., Vich, A. 2018. Analyzing the oscillations of the Perito Moreno glacier, using time lapse image sequences. Cold Region and Science Technology 146, 155-166. https://doi.org/10.1016/j. coldregions.2017.11.015.

Liss, V.C. 1970. Der Morenogletscher in der Patagonischen Kordillere: sein ungewohnliches verhalten seit 1899 und der eisdamm durchbruch des jahres 1966. Zeitschrift fur Gletscherkunde und Glazialgeologie (1), 161-180.

Lo Vecchio, A., Lenzano, M.G., Durand, M., Lannutti, E., Bruce, R., Lenzano, L. 2018. Estimation of surface flow speed and ice surface temperature from optical satellite imagery at Viedma glacier, Argentina. Global and Planetary Change 169, 202-213. https://doi.org/10.1016/j. gloplacha.2018.08.001.

Malz, P., Meier, W., Casassa, G., Jaña, R., Skvarca, P., Braun, M. 2018. Elevation and mass changes of the Southern Patagonia Icefield derived from TanDEM-X and SRTM data. Remote Sensing, 10 (2), 188. https://doi.org/10.3390/rs10020188.

Mandel, J. 1964. The Statistical Analysis of Experimental Data. New York: Interscience. https:// archive.org/stream/MandelJ.TheStatisticalAnalysisOfExperimentalData1964/Mandel+J.++The+statistical+analysis+of+experimental+data+\%281964\%29_djvu.txt 
Meier, M.F., Post, A. 1987. Fast tidewater glaciers. Journal of Geophysical Research: Solid Earth 92 (B9), 9051-9058. https://doi.org/10.1029/JB092iB09p09051.

Minowa, M., Sugiyama, S., Sakakibara, D., Sawagaki, T. 2015. Contrasting glacier variations of glaciar perito moreno and glaciar ameghino, southern Patagonia icefield. Annals of Glaciology, 56 (70), 26-32. https://doi.org/10.3189/2015AoG70A020.

Minowa, M., Sugiyama, S., Sakakibara, D., Skvarca, P. 2017. Seasonal variations in ice-front position controlled by frontal ablation at Glaciar Perito Moreno, the Southern Patagonia Icefield. Frontiers in Earth Science 5, UNSP-1. https://doi.org/10.3389/feart.2017.00001.

Minowa, M. 2017. Frontal ablation of Glaciar Perito Moreno, a lake-terminating glacier in Patagonia. PhD Thesis. Course in Cryosphere Science Hokkaido University. 129. https:// eprints.lib.hokudai.ac.jp/dspace/.../Masahiro_Minowa.pdf.

Pasquini, A.I., Depetris, P.J. 2011. Southern Patagonia's Perito Moreno glacier, Lake Argentino, and Santa Cruz River hydrological system: an overview. Journal of Hydrology 405 (1): 4856. https://doi.org/10.1016/j.jhydrol.2011.05.009.

Rao, S.S. 2009. Engineering optimization: theory and practice. John Wiley \& Sons. https://doi. org/10.1002/9780470549124.

Richter, A., Groh, A., Horwath, M., Ivins, E., Marderwald, E., Hormaechea, J. L.,... Dietrich, R. 2019. The Rapid and Steady Mass Loss of the Patagonian Icefields throughout the GRACE Era: 2002-2017. Remote Sensing, 11 (8), 909. https://doi.org/10.3390/rs11080909.

Rignot, E., Rivera, A., Casassa, G. 2003. Contribution of the Patagonia Icefields of South America to sea level rise. Science 302, 434-437. https://doi.org/10.1126/science.1087393.

Rivera, A. 1992. El Glaciar Pío XI: avances y retrocesos, el impacto sobre su entorno durante el presente siglo. Revista Geográfica de Chile Terra Australis 36, 33-62.

Rivera, A., Lange, H., Aravena, J. C., Casassa, G. 1997. The 20th-century advance of Glaciar Pio XI, Chilean Patagonia. Annals of Glaciology 24, 66-71. https://doi.org/10.3189/ S0260305500011952.

Rivera, A., Casassa, G. 1999. Volume changes on Pio XI glacier, Patagonia: 1975-1995. Global and Planetary Change 22 (1-4), 233-244. https://doi.org/10.1016/S0921-8181(99)00040-5.

Rott, H., Stuefer, M., Siegel, A., Skvarca, P., Eckstaller, A. 1998. Mass fluxes and dynamics of Moreno glacier, southern Patagonia icefield. Geophysical Research Letters, 25 (9), 14071410. https://doi.org/10.1029/98GL00833.

Sakakibara, D., Sugiyama, S. 2014. Ice-front variations and speed changes of calving glaciers in the Southern Patagonia Icefield from 1984 to 2011. Journal of Geophysical Research: Earth Surface 119 (11), 2541-2554. https://doi.org/10.1002/2014JF003148.

Sersic, J.L., 1988. Ensayos sobre el glaciar Moreno. Academia Nacional de Ciencias, Argentina.

Skvarca, P., Naruse, R. 1997. Dynamic behavior of Glaciar Perito Moreno, southern Patagonia. Annals of Glaciology 24, 268-271. https://doi.org/10.3189/S0260305500012283.

Skvarca, P., Naruse, R. 2005. Correspondence. Overview of the ice-dam formation and collapse of Glaciar Perito Moreno, southern Patagonia, in 2003/2004. Journal of Glaciology 52 (177), 318-320. https://doi.org/10.3189/S0022143000208666.

Solomina, O.N., Bradley, R.S., Jomelli, V., Geirsdottir, A., Kaufman, D.S., Koch, J., MaKay, N.P., Masiokas, M., Miller, G., Nesje, A., Nicolussi, K., Owen, L.A., Putnam, A.E., Wanner, H., Wiles, G., Yang, B. 2016. Glacier fluctuations during the past 2000 years. Quaternary Science Reviews, 149 (October), 61-90. https://doi.org/10.1016/j.quascirev.2016.04.008.

Stuefer, M. 1999. Investigations on mass balance and dynamics of Moreno Glacier based on field measurements and satellite imagery. PhD Thesis. Dissertation zur Erlangung des akademischen Grades eines Doktors der Naturwissenschaften an der Leopold-FranzensUniversitat Innsbruck. 163. 
Subasi, M., Yildirim, N., Yildiz, B. 2004. An improvement on Fibonacci search method in optimization theory. Applied Mathematics and Computation 147 (3), 893-901. https://doi. org/10.1016/S0096-3003(02)00828-7.

Sugiyama, S., Skvarca, P., Naito, N., Enomoto, H., Tsutaki, S., Tone, K., Marinsek, S., Aniya, M. 2011. Ice speed of a calving glacier modulated by small fluctuations in basal water pressure. Nature Geoscience 4 (9), 597. https://doi.org/10.1038/ngeo1218.

Sugiyama, S., Minowa, M., Sakakibara, D., Skvarca, P., Sawagaki, T., Ohashi, Y., Naito, N., Chikita, K. 2016. Thermal structure of proglacial lakes in Patagonia. Journal of Geophysical Research: Earth Surface 121 (12), 2270-2286. https://doi.org/10.1002/2016JF004084

Villalba, R., Lara, A., Boninsegna, J.A., Masiokas, M., Delgado, S., Aravena, J.C., Roig, F.A., Schmelter, A., Wolodarsky, A., Ripalta, A. 2003. Large-scale temperature changes across the southern Andes: 20th-century variations in the context of the past 400 years. In: Climate Variability and Change in High Elevation Regions: Past, Present \& Future. Springer, Dordrecht, pp. 177-232. https://doi.org/10.1007/978-94-015-1252-7_10.

Walder, J.S., Costa, J.E. 1996. Outburst floods from glacier-dammed lakes: the effect of mode of lake drainage on flood magnitude. Earth Surface Processes and Landforms 21 (8), 701-723. https://doi.org/10.1002/(SICI)1096-9837(199608)21:8<701::AID-ESP615>3.0.CO;2-2.

Warren, C.R., Rivera, A., Post, A. 1997. Greatest Holocene advance of glaciar Pío XI, Chilean Patagonia: possible causes. Annals of Glaciology 24, 1-115. https://doi.org/10.3189/ S026030550001185X.

Willis, M.J., Melkonian, A.K., Pritchard, M.E., Rivera, A. 2012. Ice loss from the Southern Patagonian Ice Field, South America, between 2000 and 2012. Geophysical Research Letters 39, 1-6. https://doi.org/10.1029/2012GL053136.

Wu, D., Lu, Z., Wang, Y., Cheng, L. 2015. Model validation and calibration based on component functions of model output. Reliability Engineering \& System Safety 140, 59-70. http://doi. org/10.1016/j.ress.2015.03.024 
